UNIVERSIDADE DE SÃO PAULO

FACULDADE DE MEDICINA DE RIBEIRÃO PRETO

\title{
DENSIDADE MAMOGRÁFICA ANTES E APÓS O USO DE TIBOLONA: AUXÍLIO DA
}

INFORMÁTICA

Marcelo Ballaben Carloni

Dissertação apresentada à Faculdade de Medicina de Ribeirão Preto da Universidade de São Paulo, para obtenção do Título de Mestre, pelo curso de Pós-Graduação em Medicina.

Área de concentração: Tocoginecologia.

Orientador: Prof. Dr. Hélio Humberto Angotti Carrara.

RIBEIRÃO PRETO - SP 


\section{Ficha Catalográfica}

\section{Carloni, Marcelo Ballaben}

Densidade mamográfica antes e após o uso de tibolona: auxílio da informática. Ribeirão Preto, 2006.

75 p.:il.; $30 \mathrm{~cm}$

Tese de Mestrado, apresentada à Faculdade de Medicina de Ribeirão Preto - USP - Área de concentração: Tocoginecologia.

Orientador: Carrara, Hélio Humberto Angotti.

1. Tibolona. 2. Densidade mamária. 3. Terapia hormonal. 4. Menopausa. 5. Análise computadorizada. 6. Mamografia. 


\section{Autorização}

Autorizo a reprodução e/ou divulgação total ou parcial da presente obra, por qualquer meio convencional ou eletrônico, desde que citada a fonte.

Marcelo Ballaben Carloni

Instituição: Faculdade de Medicina de Ribeirão

Preto da Universidade de São Paulo

Local: Ribeirão Preto, São Paulo

Endereço: Av. Bandeirantes, 3900, 14048-900,

Ribeirão Preto - SP

E-mail: elisabetemarcelo@uol.com.br 


\section{Dedicatória}

À Elisabete, minha esposa e aos meus pais, Nélio e Cecília.

Obrigado pela compreensão e incentivo nas horas mais difíceis da vida. 


\section{Agradecimentos}

Ao amigo e orientador Prof. Dr. Hélio Humberto Angotti Carrara pelo incentivo constante e pelo exemplo de caráter ético e profissional.

Aos professores e amigos do Departamento de Ginecologia e Obstetrícia da Faculdade de Medicina do Triângulo Mineiro, pela minha formação acadêmica e profissional.

Aos professores do Departamento de Ginecologia e Obstetrícia da Faculdade de Medicina de Ribeirão Preto pela oportunidade e confiança.

Aos professores do C.S.E Cuiabá pela compreensão durante a coleta de dados.

Aos funcionários do departamento de Ginecologia e Obstetrícia e pósgraduação em Ginecologia e obstetrícia pelo apoio.

Aos Drs. Paulo Mazzoncini Azevedo Marques e Marcelo Honda pela orientação e trabalho conjunto.

Aos Drs. Valdair Francisco Muglia e Jorge Elias Junior pela contribuição profissional.

Aos professores e funcionários da radiologia pela paciência durante a realização do estudo. 


\section{Sumário}

Resumo

Summary

1. Introdução

1.1. Terapia Hormonal - Histórico ............................................ 2

1.2. Terapia Hormonal - Esquemas.......................................... 2

1.3. Terapia Hormonal - Tibolona ............................................. 4

1.4. Terapia Hormonal - Objetivos ......................................... 4

1.5. Terapia Hormonal - Endométrio ........................................ 6

1.6. Terapia Hormonal - Mama................................................... 7

1.7. Mamografia - Histórico ................................................. 9

1.8. Mamografia - Variação da Densidade .................................. 9

2. Objetivo.................................................................................. 12

3. Desenho do Estudo .................................................................... 14

4. Casuística e Metodologia......................................................... 16

4.1. Seleção de Pacientes....................................................... 17

4.2. Exames Iniciais e Acompanhamento................................. 18

4.3. Realização das Mamografias ........................................... 19

4.4. Análise das Grafias ........................................................ 22

4.5. Análise Estatística.......................................................... 25

4.6. Redação do Texto ............................................................. 26 


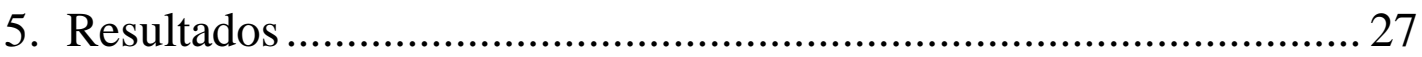

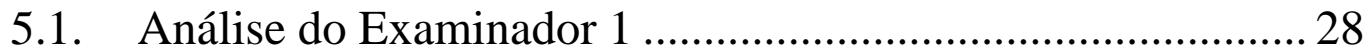

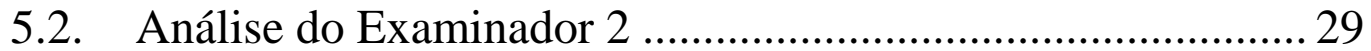

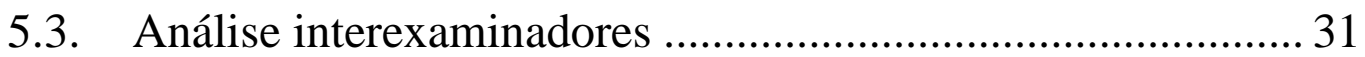

5.4. Análise Computadorizada da Densidade Mamográfica ......... 32

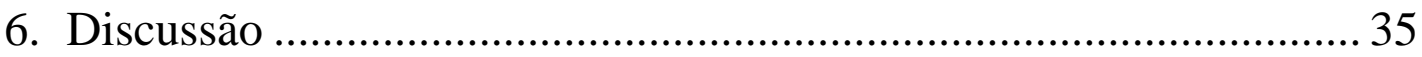

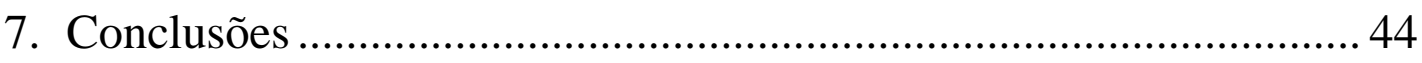

8. Referências Bibliográficas ................................................................ 46

Anexos 


\section{Resumo}

A terapia hormonal na menopausa tem sido objeto de muita contradição nos últimos anos, pois trabalhos mostram resultados contraditórios quanto a benefícios e riscos para as usuárias. Ficou demonstrada, em alguns trabalhos, a maior incidência de carcinoma de mama em usuárias de terapia hormonal clássica e, portanto, existe uma constante busca no que diz respeito ao refinamento de métodos diagnósticos e avaliação dos efeitos das novas drogas na mama. Dentre as drogas mais modernas, a tibolona vem se destacando por apresentar poucos efeitos colaterais, principalmente relacionados à mama. Esta droga apresenta três metabólitos com ação tecidual específica. Assim, efeitos androgênicos, estrogênicos ou progesterônicos podem ser observados na dependência do órgão alvo estudado. Os objetivos de nosso estudo foram avaliar um método de análise computadorizada da densidade mamográfica e, ao mesmo tempo, avaliar os efeitos da tibolona na densidade dessas mamografias. Em nosso estudo, foram avaliadas 26 pacientes na pós menopausa e que tinham indicação do uso de terapia hormonal oral, de acordo com o protocolo vigente no Setor de Endocrinologia Ginecológica do Centro de Saúde Escola da Faculdade de Medicina de Ribeirão PretoUSP. Essas pacientes receberam tibolona na dose de 2,5 mg/dia por 24 semanas. Todas foram submetidas à mamografia antes a após o uso da droga sendo, durante a realização do exame, colocado sobre a plataforma de compressão da mama (Buck) um objeto de referência (escala em acrílico confeccionada para essa finalidade) na intenção de normalizar os exames pré e pós-tratamento. Além disto, as mamografias foram submetidas à avaliação de dois examinadores com o intuito de verificar variações da densidade mamográfica. Essas mesmas mamografias, após normalização pelo objeto de referência, também foram submetidas à análise computadorizada da densidade. Foram realizadas comparações entre os resultados da avaliação da densidade da mama antes e após o uso da tibolona tanto nos laudos dos examinadores, quanto nas imagens digitalizadas. Foi feito também comparação inter-examinadores. As análises comparativas das densidades das grafias antes a após o uso da tibolona não mostraram variações significativas tanto na análise dos examinadores quanto na análise computadorizada. A análise comparativa inter-examinadores mostrou uma tendência à variação entre as classificações da densidade mamográfica, apesar de não ser estatisticamente significante. Podemos concluir que a tibolona, se administrada a pacientes na pós menopausa, na dose de $2,5 \mathrm{mg} /$ dia por 24 semanas não causa variação da densidade mamográfica. Desta forma, a avaliação computadorizada da densidade mamográfica pode ser usada como método auxiliar aos radiologistas, em casos de mamas mais densas permitindo uma melhor avaliação desses casos.

Palavras-chave: Tibolona; densidade mamária; terapia hormonal; menopausa; análise computadorizada; mamografia. 


\section{Summary}

Over the last few years, hormonal therapy has been subject of much controversy since various studies have shown contradictory results regarding the risks and benefits for users. A higher incidence of breast carcinoma among users of classical hormonal therapy has been demonstrated in some studies and therefore there is a constant search regarding the refinement of diagnostic methods and the evaluation of the effects of new drugs on the breast. Among the more modern drugs, tibolone is particularly outstanding because it has few side effects, especially related to the breast. This drug has three metabolites with specific tissue action. Therefore, androgenic, estrogenic or progestogenic effects can be achieved, depending on the organ evaluated. The objectives of the present study were to assess a computerized method for the analysis of mammographic density. The author evaluated 26 menopausal women with an indication for oral hormonal therapy according to the protocol of the sector of gynecologic endocrinology of the Faculty of Medicine of Ribeirão Preto, USP. Tibolone at the dose of $2.5 \mathrm{mg} /$ day was administered to these patients for 24 weeks. The patients were submitted to mammography before and after the use of the drug. During the exam, a reference object (an acrylic scale prepared for this purpose) was placed on the platform for breast compression (Buck) in order to normalize the pre- and post-treatment exams. In addition, two examiners evaluated the mammographies in order to determine variations in mammographic density. After normalization according to the reference object, these same mammographies were submitted to computerized density analysis. The mamographic density results obtained before and after the use of tibolone are compared in the digitalized images and in the examiners evaluation. In the same way, an inter-examiners analysis was done. The comparative analyses of the mammographic densities before and after the use of tibolone did not show significant variations in the analyses of the examiners or in the computerized analysis. Inter-examiner analysis showed a tendency to variation in the classification of mammographic density, although the difference was not statistically significant. The author concluded that tibolone, when administered to menopausal women at the dose of $2.5 \mathrm{mg} /$ day for 24 weeks, did not cause a variation in mammographic density. Computerized evaluation of mammographic density can be used as an auxiliary method to radiologists, in cases of high density breast mammography, allowing a more confident evaluation of these cases.

Key words: Tibolone; breast density; hormonal therapy; menopause; computerized analysis; mammography. 
1. INTRODUÇÃO 


\subsection{Terapia Hormonal - Histórico}

A partir de 1960, o segmento mais velho da população dos países desenvolvidos tem crescido mais rapidamente que o mais jovem (SPEROFF et al., 1995). Com o aumento da expectativa de vida da população mundial, esse fenômeno não será apenas dos países ricos. À medida que a população envelhece, procuram-se criar terapias para melhoria da qualidade de vida em idades mais avançadas. Dentre essas terapias, a mais difundida para o sexo feminino é a terapia hormonal $(\mathrm{TH})$.

Existem vários tipos de terapia hormonal. As mais usadas e tradicionais são aquelas que utilizam hormônios estrogênicos associados ou não com progestogênicos. Menos usados e mais recentes são os moduladores seletivos de receptores estrogênicos (Selective Estrogen Receptors Modulators-SERMs), como por exemplo, o raloxifeno e medicações que atuam por ação tecidual específica como a tibolona. Algumas vezes, os androgênios.podem também ser utilizados para tal fim.

\subsection{Terapia Hormonal - Esquemas}

Segundo Bagnoli et al. (2001), os esquemas clássicos de terapia de reposição hormonal podem ser divididos em cinco modos de administração de acordo com a indicação.

O esquema contínuo simples consiste na administração de apenas a medicação estrogênica sem associações e, normalmente, é usado em casos de mulheres histerectomizadas. Esse esquema simples pode ser usado principalmente em dois casos: em mulheres que não possuem útero, administra-se apenas medicação de efeito estrogênico durante três semanas por mês; nas não histerectomizadas na peri-menopausa, usam-se progestágenos durante dez a doze dias por mês até não haver mais sangramento de privação. 
Mulheres que desejam o fluxo menstrual devem utilizar os esquemas: combinado cíclico contínuo ou combinado cíclico seqüencial. Esses consistem em administrar o estrogênio de forma contínua em associação com a progesterona de forma cíclica, ou a administração de ambos de forma cíclica respectivamente.

O quinto esquema que pode ser citado é o combinado contínuo, em que não há sangramento de privação e que consiste no uso de estrogênio e progesterona de forma contínua.

Outra variação dos esquemas clássicos é referente à via de administração; dentre essas podemos citar a via oral e parenteral. Essa última é dividida em transdérmica, implante subcutâneo, spray nasal, vaginal, intramuscular e dispositivos intra-uterinos com progesterona.

A via oral é melhor indicada para as mulheres com níveis elevados de colesterol e tem como vantagem o baixo custo. Já a via parenteral é especíica para mulheres hipertensas, com níveis elevados de triglicerídeos, diabéticas, fumantes e portadoras de distúrbios gastrointestinais (BAGNOLI et al., 2001).

Mais recentemente tem-se dado especial atenção à terapia hormonal de baixa dose. Estudos têm sido publicados demonstrando a efetividade desse esquema na manutenção da matriz óssea, melhoria do perfil lipídico e dos sintomas climatéricos (DELMAS et al., 2000; BAERUG et al., 1998; LOBO et al., 2001). 


\subsection{Terapia Hormonal - Tibolona}

Uma das opções em relação à terapia de reposição hormonal tradicional é a tibolona que é um hormônio esteróide sintético, derivado do noretinodrel, que apresenta três metabólitos, a saber: $3 \alpha-\mathrm{OH}, 3 \beta-\mathrm{OH}$ e $\Delta 4$ tibolona. Esses apresentam uma ação tecidual específica, ou seja, têm efeitos estrogênicos, progestogênicos e androgênicos de acordo com os seus órgãos alvos (von HOLST, 2000; PALACIOS, 2001).

A tibolona funciona como uma pré-droga que é metabolizada em componentes que ativam receptores nucleares de androgênios e progestogênios que, por sua vez, modificam os níveis dos receptores e o metabolismo estrogênico (MAUDELONDE et al., 1999). Estudos realizados com animais demonstraram que esta droga possui uma atividade estrogênica quinze vezes menor que o etinilestradiol, atividade progesterônica oito vezes inferior à noretisterona e um terço da atividade androgênica desta última (NETO et al., 2001).

\subsection{Terapia Hormonal - Objetivos}

Dentre os principais objetivos a serem alcançados com a administração de hormônios na pós-menopausa estão a prevenção da osteoporose, de alterações cardiovasculares e do sistema nervoso central.

A terapia de reposição hormonal atua de várias formas na prevenção da osteoporose, sendo uma das mais importantes a remodelação óssea, pela inibição da reabsorção do osso (ERIKSEN et al., 1988). O uso do esquema tradicional de TH, ou da tibolona, diminuiu a perda óssea e os níveis das enzimas de reabsorção óssea em relação ao grupo placebo, provando ser a TH efetiva na prevenção da osteoporose em mulheres menopausadas (STUDD et al., 1998; LIPPUNER et al., 1997; ROUX et al., 2002). 
$\mathrm{Na}$ prevenção de alterações cardiovasculares, a terapia de reposição hormonal demonstrou ser útil, melhorando o perfil lipídico (LOBO, 1990) e lipoproteico (SACK, 1994), através de efeito antiaterosclerótico direto sobre as artérias (WILLIAMS, 1990) e com efeito vasodilatador coronariano através do aumento das prostaglandinas e a diminuição dos tromboxanos (PALACIOS, 1993; STENVENSON, 1995). Além desses, ainda se demonstrou a ação inotrópica direta sobre o coração e a melhora do metabolismo periférico da glicose (SPEROFF et al., 1995).

No sistema nervoso central, os estrogênios influenciam a síntese de proteínas e de fatores de crescimento (BIRGE, 1997), aumentam a densidade dendrítica, melhoram o fluxo sanguíneo cerebral e os níveis de neurotransmissores e diminuem o estresse oxidativo (HENDERSON et al., 1994). Stritmater et al. (1993) e Greene (2000) descreveram ainda a atenuação do risco de doença de Alzheimer em usuárias de terapia hormonal.

Além das ações citadas acima, a terapia hormonal tem sido empregada por proporcionar a melhora de sintomas vasomotores, emocionais, tegumentares, musculares e urogenitais, muito comuns em mulheres na pós menopausa.

A terapia hormonal atua diminuindo os fogachos por mecanismos ainda não bem esclarecidos (NOTELOVITZ \& MATTOX, 2000; IMTHURN \& MAURER-MAJOR, 2000). Os fogachos poderiam estar intimamente ligados a sintomas psicológicos causando ansiedade, perda de sono e irritabilidade (FONSECA, 2001). Por outro lado, a falta de estrogênios no cérebro diminui a quantidade de serotonina que pode resultar em depressão (SARREL et al., 1994).

A diminuição substancial de colágeno e de elastina podem ser evitadas com a terapia hormonal, prevenindo, dessa forma, a perda do tônus muscular e tegumentar, principalmente da pele (WISEMAN \& O’REILLY, 1997). 
Os sintomas urogenitais, principalmente a incontinência urinária, provêm do aumento do relaxamento dos músculos e ligamentos genitourinários, diminuição da espessura da parede da uretra e dos tecidos que a circundam, levando a um fechamento incompleto da mesma, o que pode ser evitado com o uso de terapia hormonal (BACHMANN et al., 1994).

Apesar das vantagens, o uso de TH tem sido alvo de preocupação em relação aos efeitos desses hormônios no tecido mamário e endometrial. Vários estudos tentaram esclarecer dúvidas sobre esses efeitos, sendo alguns de maior porte e controlados.

\subsection{Terapia Hormonal - Endométrio}

Em relação ao endométrio, estudos demonstraram ser seguro o uso de reposição hormonal de acordo com os diferentes esquemas existentes (PERSSON et al., 1989).

Egarter et al. (1996) e Hammar et al. (1998) demonstraram não haver espessamento endometrial e existir baixa incidência de sangramento vaginal em pacientes usuárias, tanto da reposição hormonal tradicional quanto da tibolona, apesar de serem mais freqüentes nas usuárias do primeiro esquema.

A segurança da tibolona também vem sendo avaliada do ponto de vista da incidência de carcinoma de endométrio. Beral et al. (2005) publicaram estudo com 716738 pacientes demonstrando um maior aumento de câncer de endométrio em usuárias de tibolona se comparada a outras terapias, inclusive estrogênios. Todavia, se levarmos em conta que as terapias contendo estrogênios em associação com progesterona apresentam um aumento da incidência de câncer de mama, a incidência global de câncer (mama e endométrio) é menor em usuárias de tibolona. O aumento da incidência de câncer de endométrio em usuárias de tibolona também pode resultar do fato dessa terapia ser mais indicada para mulheres de maior risco para essa patologia (JAMIN et al., 2006). 


\subsection{Terapia Hormonal - Mama}

Em relação à mama, demonstrou-se o aumento da incidência de câncer de mama com o uso de TH com esquemas tradicionais por longo período (COLDITZ et al., 1995). Esse aumento decresce após a interrupção do uso da medicação e desaparece cerca de cinco anos após (COLLABORATIVE GROUP ON HORMONAL FACTORS IN BREAST CANCER, 1997; CHIECHI \& SECRETO, 2000).

Um marco em relação à terapia hormonal foi o estudo denominado Womem's Health Initiative (WHI) publicado em 2002, em que um segmento do estudo foi interrompido pelo aumento significativo do risco para carcinoma invasivo de mama em pacientes usuárias de terapia hormonal no esquema contínuo combinado de Estrogênios Eqüinos Conjugados 0,625mg e Acetato de Medroxiprogesterona 2,5mg. Foi o primeiro estudo realmente completo, com boa metodologia, com grande número de pacientes e significativo tempo de seguimento abordando a TH (WRITING GROUP FOR THE WOMEN'S HEALTH INITIATIVE INVESTIGATORS, 2002). Mesmo assim, até esse estudo foi passível de críticas, pelo fato de ter incluído mulheres que iniciaram a terapia hormonal em idade mais avançada e pelo fato de apenas um tipo de terapia ter sido avaliado (KLAIBER et al.,2005).

Apesar do aumento da incidência de câncer de mama em usuárias de reposição hormonal por longo prazo, observou-se, paradoxalmente, a diminuição da mortalidade causada por essa neoplasia nas pacientes que tiveram o diagnóstico feito durante o uso da mesma (COBLEIGH et al., 1999).

Squitieri et al. (1994) e Holli et al. (1998) sugeriram que a terapia de reposição hormonal apresentaria efeito inibitório direto sobre o crescimento neoplásico, o que explicaria o crescimento mais lento e o estágio mais precoce de tumores em mulheres usuárias de reposição hormonal em relação a não usuárias. Corroborando esse fato, ficou 
demonstrado que as usuárias de reposição hormonal apresentavam tumores com tipo histológico mais favorável (MAYER, 1999).

Em mulheres que tiveram o diagnóstico de neoplasia maligna da mama durante o uso de hormônios na menopausa, demonstrou-se maior incidência de tumores bem diferenciados, menor incidência de tumores localmente avançados e maior sobrevida livre de metástase (BONNIER et al., 2000).Por esses motivos, procuraram-se opções mais seguras de TH.

Uma alternativa em relação à terapia hormonal clássica e que vem aumentando de importância é a tibolona. Ela vem sendo prescrita preferencialmente para pacientes com alterações mamárias prévias, mamas mais densas na mamografia e na vigência de maior risco para câncer de mama (JAMIN et al., 2006). Esse fato pode estar relacionado ao aumento da incidência de câncer de mama, relatado na literatura, em mulheres usuárias de tibolona (BERAL, 2003).

Por outro lado, alguns autores demonstram ser a tibolona uma terapia hormonal de grande segurança, usando-a, inclusive, em pacientes já tratadas para câncer de mama. Dimitrakakis et al. (2005) publicaram estudo com 156 mulheres já tratadas para câncer de mama. Destas, 52 usaram tibolona por um período médio de 61 meses não sendo encontrado aumento da incidência de recorrência e da densidade mamária. Neste mesmo estudo, o autor descreve a ocorrência de uma importante melhora dos sintomas climatéricos nas pacientes.

Ainda para se tentarem analisar os efeitos da tibolona em pacientes portadoras de câncer de mama, Vanhoecke et al. (2006) desenvolveram estudo in vitro em que demonstraram haver um efeito anti-invasivo da tibolona e de seu metabólito $3 \beta-\mathrm{OH}$ em células de câncer de mama. 


\subsection{Mamografia - Histórico}

Com o crescimento da incidência do câncer de mama nos países desenvolvidos, aumentou-se também a preocupação com métodos de detecção precoce. Por outro lado, não houve grandes nem recentes evoluções em relação a esses.

As primeiras menções à radiografia da mama datam de 1913, quando Albert Salomon usou-as para avaliar a disseminação tumoral em peças cirúrgicas de mastectomia. A mamografia in vivo foi descrita pela primeira vez em 1930, em Nova York, por Stafford Warren (PASQUALETTE, 1998).

A mamografia continua, até os dias atuais, sendo considerada o método "gold standard” para encontrar lesões mamárias pré clínicas (HEYWANG-KÖBRUNNER et al., 1999).

\subsection{Mamografia - Variação da Densidade}

A acuidade da mamografia é inversamente proporcional à densidade da mama analisada durante o exame, sendo quanto mais densa a mama mais difícil a avaliação da mesma (HOMER, 1985; PAGE e WINFIELD, 1986; JACKSON et al., 1993; MANDELSON et al., 2000).

Outro fator que tem relevância em relação à precisão da avaliação mamográfica é o método de interpretação das mamografias. A maneira mais usada para classificar a densidade mamográfica divide as mamografias de forma descritiva, ou seja, em predominantemente lipossubstituídas, densidades fibroglandulares dispersas, mamas heterogeneamente densas, mamas extremamente densas. Essa classificação, proposta pelo Colégio Americano de Radiologia, é denominada Breast Imaging Reporting and Data 
System - BI-RADS e tem como objetivo a padronização dos laudos mamográficos e das condutas perante a análise mamográfica (KERLIKOWSKE et al., 1998; BERG et al., 2000).

Leung et al. (1997) e Kaufman et al. (1991) observaram um aumento da densidade mamográfica em pacientes usuárias da terapia de reposição hormonal tradicional.

Erel et al. (2001), Sendag et al. (2001), Bülbül et al (2003) encontraram aumento da densidade mamográfica tanto em pacientes que usaram reposição hormonal tradicional quanto em usuárias de tibolona, sendo esse aumento maior no primeiro grupo e, principalmente, em regimes com uso de progestogênios combinados contínuos. Já Colacurci et al. (2001) encontraram esse aumento em usuárias de reposição hormonal via transdérmica com estrogênios, com ou sem adição de progestágenos, enquanto a variação da densidade mamográfica não foi significante nas usuárias de tibolona.

Em estudo comparativo entre tibolona e raloxifeno, ficou demonstrado que a densidade mamográfica aumentou respectivamente em 10,7\% nas usuárias de tibolona e 6,3\% nas usuárias de raloxifeno, não parecendo interferir na interpretação do exame (CHRISTODOULAKOS et. al., 2002.

Com o aumento da densidade mamográfica causada pela $\mathrm{TH}$, haveria maior dificuldade de interpretação das grafias, diminuindo a sensibilidade desse método para diagnóstico de tumores, principalmente nas suas fases iniciais, repercutindo negativamente nos programas de rastreamento mamográfico (FAJARDO et al., 1988; KERLIKOWSKE et al., 1998).

Wolfe et al. (1987) e Byrne et al. (1995) relacionaram densidade mamográfica elevada ao aumento do risco para câncer de mama. Corroborando esse estudo, van Gils et al. (1999) relacionaram a diminuição da densidade mamária em mulheres menopausadas com o menor risco para câncer de mama. 
Ozdemir et al. (1999) analisaram a variação da densidade das grafias mamárias e alterações ultrassonográficas em relação a vários tipos de terapia de reposição hormonal. Foi encontrado um aumento significativo da densidade mamográfica em usuárias de estogênios conjugados associados a acetato de ciproterona (46\%) e a medroxiprogesterona (43\%) quando comparadas a usuárias de tibolona (28\%) e estrogênio puro (18\%). Nesse mesmo estudo não houve variação das alterações ultrassonográficas em todos os grupos.

Demonstrou-se, em estudo randomizado, que existe um aumento significativo na densidade mamária e da mastodínea em usuárias de estrogênio transdérmico associado a acetato de normegestrol $5 \mathrm{mg} /$ dia, em esquema seqüencial, em comparação a usuárias de tibolona na dose de $2,5 \mathrm{mg} / \mathrm{dia}$ contínuo. Com esses dados, os autores concluíram ser a tibolona a medicação de primeira escolha em pacientes com densidade mamária aumentada e portadoras de alterações benignas da mama (COLACURCI et al., 1998).

Corroborando esse dado, Egarter et al. (2001) encontraram uma diminuição da densidade mamária e melhora do desconforto mamário em mulheres na pós menopausa, com mastopatia, após seis meses de uso de tibolona na dose de 2,5 mg por dia.

Conforme observado acima, torna-se evidente que a ação da tibolona no tecido mamário ainda não está bem definida. Consequentemente, ainda permanecem algumas dúvidas em relação às alterações mamográficas induzidas pela administração da tibolona em mulheres menopausadas. 
2. OBJETIVO 
1. Verificar as possíveis alterações na densidade mamográfica determinadas pela ação da tibolona, observadas de modo subjetivo (através de examinadores) e objetivo (através da leitura computadorizada) com controle pré e pós-tratamento com esta terapia. 
3. DESENHO DO ESTUDO 
Estudo prospectivo controlado, de intervenção, do tipo antes-e-depois, sendo cada participante do estudo seu próprio controle. 


\section{CASUÍSTICA E METODOLOGIA}




\subsection{Seleção de Pacientes}

A casuística do trabalho constou de mulheres que foram atendidas no Setor de Endocrinologia Ginecológica do Centro de Saúde Escola Cuiabá da FMRP-USP com queixas de climatério. Aquelas que tinham desejo de Terapia Hormonal (TH) oral segundo o protocolo vigente naquele Centro e que preenchiam os critérios de inclusão deste projeto, foram selecionadas e entrevistadas com o objetivo de fazer parte do trabalho. Os dados da anamnese e do exame físico realizados eram anotados em formulário no qual, posteriormente, seriam incluídos os resultados dos exames complementares e os dados das mamografias (Anexo 1).

Os seguintes critérios de inclusão das pacientes foram considerados:

- $\quad$ serem pós-menopausadas;

- $\quad$ apresentarem sintomas climatéricos;

- não apresentarem patologia maligna mamária;

- não serem de alto risco para patologia maligna da mama;

- não apresentarem patologia ginecológica que contra-indicasse TH;

- $\quad$ aceitarem TH por via oral;

- $\quad$ terem idade inferior a 65 anos;

- concordarem em participar do estudo e assinarem o Termo de Consentimento Informado.

Da mesma forma, consideraram-se os seguintes critérios de exclusão das pacientes:

- passado de doença trombo-embólica;

- passado ou presença de patologia maligna da mama;

- patologia ginecológica que contra-indicasse TRH;

- $\quad$ sangramento uterino anormal; 
- Terem usado medicamento hormonal nos três meses que antecederam o início do estudo.

Essas pacientes foram submetidas a exame clínico, citologia oncótica cérvico-vaginal e a exames laboratoriais de rotina, conforme protocolo vigente no setor (Anexo 2).

Para se detectar uma variação de densidade mamária de $8 \%$ nas grafias com poder de teste de $80 \%$ e nível de significância de 0,05 o cálculo amostral obteve como resultado 26 pacientes.

O tempo de 24 semanas para reavaliação dos efeitos da tibolona na mama foi baseado na sua farmacodinâmica e em estudos realizados anteriormente (LUNDSTRÖM et al., 2002)

Trinta e quatros mulheres satisfizeram estes critérios e, após assinatura do Termo de Consentimento Informado aprovado pelo Comitê de Ética em Pesquisa do HC-FMRP-USP (Anexo 3), constituíram a casuística deste trabalho. Oito mulheres abandonaram o estudo por diferentes motivos (duas por não comparecerem aos retornos agendados, duas por intolerância gástrica à droga, duas por sangramento, uma por alergia cutânea à droga e uma por ter descontinuado a medicação por esquecimento).

\subsection{Exames iniciais e acompanhamento}

Após os exames de rotina, todas as pacientes do estudo foram submetidas a exame mamográfico, denominado Exame Inicial.

Após a liberação do laudo da mamografia e o mesmo tendo sido considerado normal (BI-RADS I e II), as pacientes receberam uma caixa de Tibolona de 2,5 mg, e foram orientadas a ingerir um comprimido ao dia, por um período de quatro semanas, em horário fixo, sendo este horário de escolha da paciente. 
Todas as pacientes foram orientadas a retornar à consulta com o pesquisador a cada vinte e oito dias para receber nova cartela da medicação, ou a qualquer momento se houvesse necessidade.

Durante estes retornos, todas as queixas das pacientes eram anotadas e também foi verificado o número de comprimidos ingeridos no período, bem como a necessidade de suspensão da droga devido a qualquer efeito colateral apresentado.

Após 24 semanas de uso da medicação, cada paciente foi submetida à nova mamografia, denominado Exame Final, obedecendo aos critérios citados a seguir. Para a realização das mamografias, tanto no Exame Inicial quanto no Exame Final, foi colocado como referência na plataforma de compreensão da mama (Buck), um objeto em acrílico (Figura 1).

\subsection{Realização das Mamografias}

Todas as mamografias foram realizadas no Setor de Radiologia do Hospital das Clínicas da Faculdade de Medicina de Ribeirão Preto - Universidade de São Paulo, sendo assistidas por técnico especializado e pelo Pesquisador.

O aparelho utilizado foi um mamógrafo da marca General Elletric modelo Senografe DMR com calibragem automática. Os filmes utilizados foram da marca Kodak, modelo MIN-R 2000 Screen.

Durante a realização dos exames, na incidência crânio caudal, foi colocado sobre a plataforma de compressão da mama (Buck) um objeto de referência (escala em acrílico confeccionada para essa finalidade) (Figura 1) junto à região anatômica em estudo, que após a revelação do filme mamográfico se mostrou como uma escala de cinza (Figuras 2 e 3 ). 
A utilização de um objeto de referência se faz necessária para normalizar as imagens, eliminando assim, variações devido ao processo de produção, aquisição e digitalização. O objeto de referência também servia para normalizar as possíveis variações de intensidade dos raios $\mathrm{X}$ entre o Exame Inicial e o Exame Final devido à carga total do aparelho, densidade $\mathrm{e}$ compressão da mama. Após ter realizado a exposição do filme, esse era revelado em reveladora da marca Kodak modelo M 35-M X-OMAT Processor com tempo médio de revelação de 90 segundos para cada grafia.

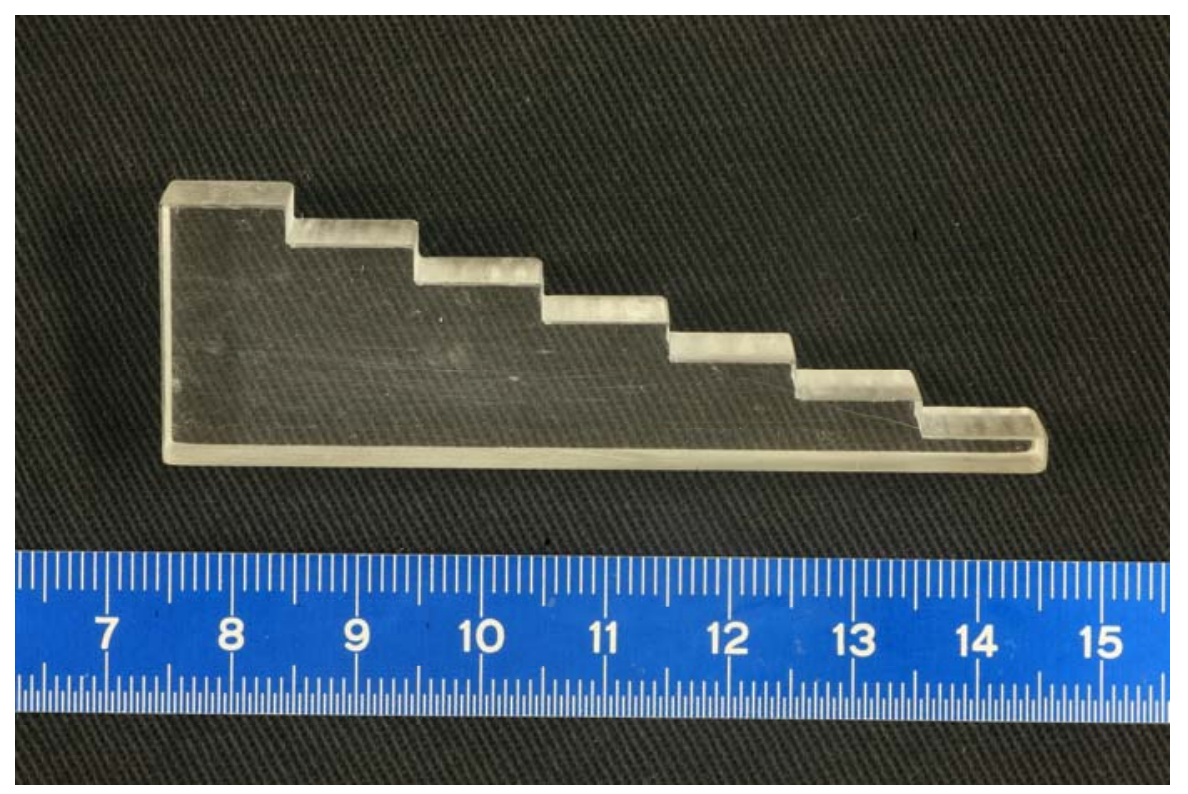

Figura 1. Escala em acrílico colocada no Buck como objeto de referência. 


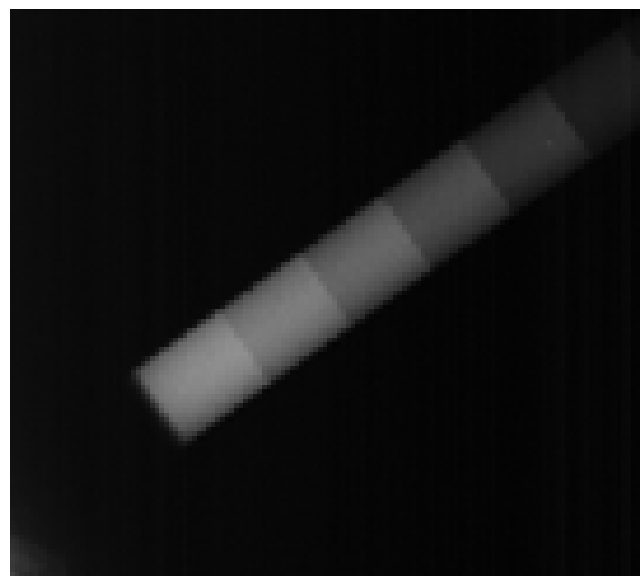

Figura 2. Escala de cinza impressa no filme radiológico pelo artefato acrílico

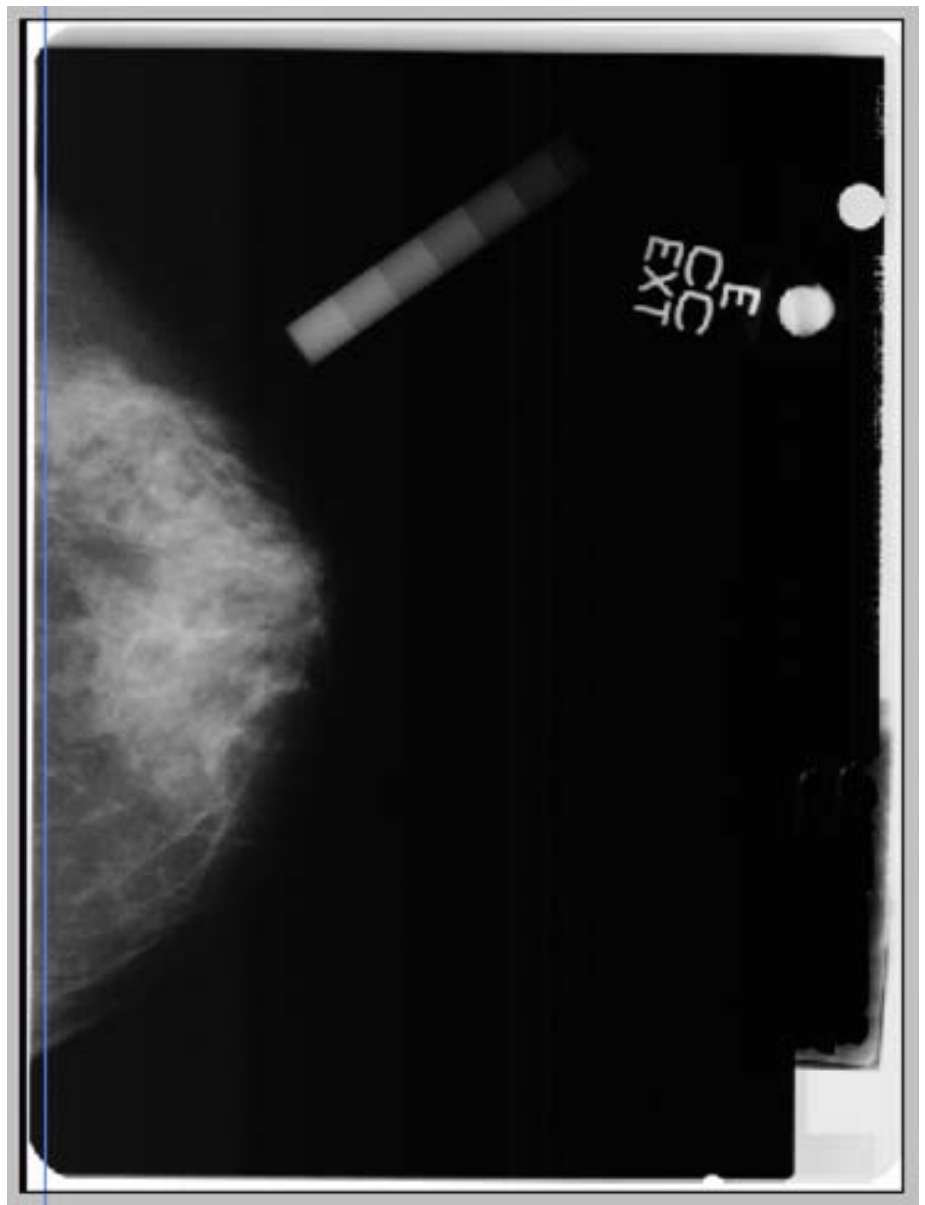

Figura 3. Grafia com escala de cinza impressa durante a realização do exame. 


\subsection{Análise das Grafias}

As grafias foram analisadas por médico radiologista e, se necessário, repetida alguma incidência, sendo, posteriormente, enviadas para laudo no setor de Radiologia do Hospital das Clínicas da Faculdade de Medicina de Ribeirão Preto.

Após a leitura e emissão do laudo da mamografia e confirmada a ausência de alterações, as grafias foram digitalizadas com scanner VIDAR DiagnosticPro (VIDAR System Corporation - Herndon - VA - USA) com 300 dpi de resolução espacial (0.084 mm pixel) e 12 bits de quantização (4096 níveis de cinza) e armazenadas em cd-rom no formato TIFF compatível com leitura com o programa Adobe Photoshop ${ }^{\circledR}$, versão 6.01, a Adobe Systems Incorporated, para Windows (Figura 4).

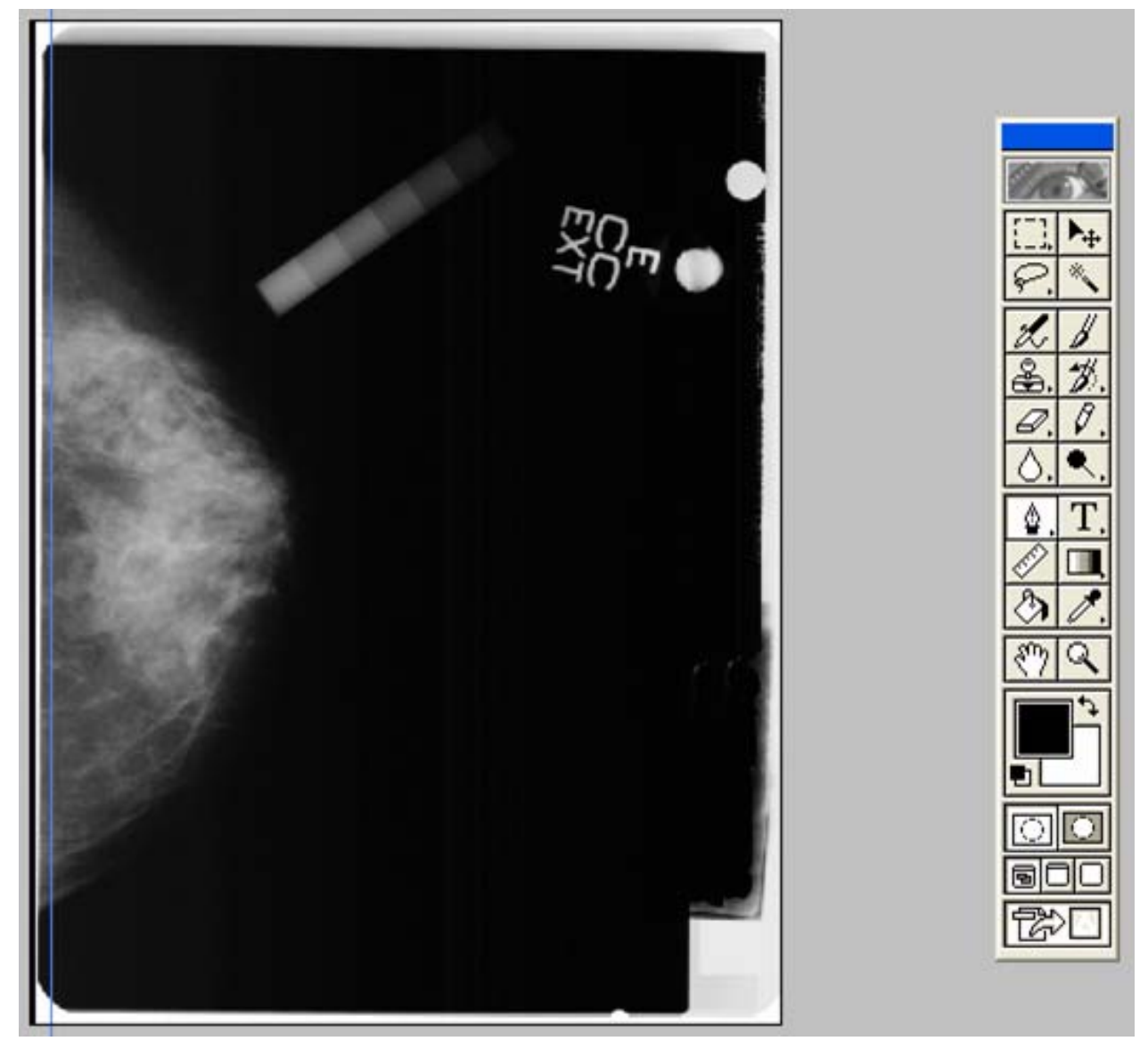

Figura 4. Leitura da grafia pelo programa Adobe Photoshop ${ }^{\circledR}$ 
Além do laudo de rotina do Setor de Radiologia, que foi usado nesse estudo para afastar eventuais alterações mamárias que pudessem ser critério de exclusão, as grafias foram ainda avaliadas por dois médicos radiologistas (J.E.J. e V.F.M.), de forma independente, em momentos diferentes e sem que um tivesse conhecimento do laudo do outro ou o laudo inicial das grafias.

A descrição da densidade mamária foi feita de acordo com a classificação para densidade mamográfica do Colégio Americano de Radiologia denominado Breast Imaging Reporting and Data System - BI-RADS (AMERICAN COLLEGE OF RADIOLOGY, 1998). Esse método, apesar de ter parâmetros já bem estabelecidos, ainda apresenta algum grau de subjetividade, por haver possibilidade de interferência por parte do examinador. A avaliação computadorizada das mamografias foi realizada usando-se as grafias após a digitalização. Como havia variação na dosagem de raios $\mathrm{X}$ entre a primeira e a segunda mamografias, usou-se a imagem obtida dos objetos de referência colocados na hora da realização da mamografia para normalizar as imagens pré e pós tratamento.

Para esta normalização, foi utilizado o valor da média e da mediana do histograma de níveis de cinza extraídos da região segmentada do objeto de referência, colocado durante a realização dos exames pré e pós tibolona (Figura 5). 

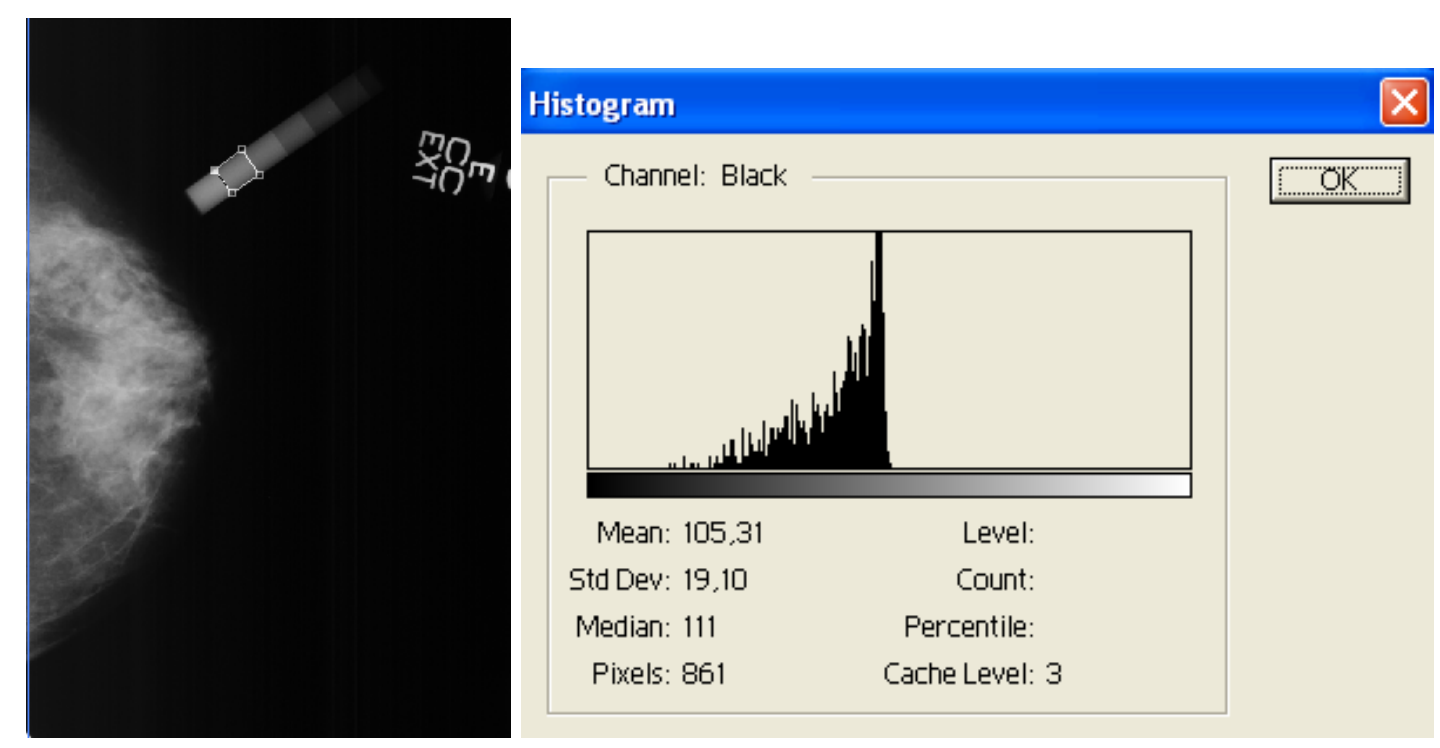

Figura 5. Avaliação da área delimitada da escala de cinza através do histograma para normalizar as imagens pré e pós tibolona.

A normalização visa deixar o valor da média e mediana de ambas as imagens coincidentes. Quando necessário, foi corrigido o brilho na imagem pré-tratamento, baseando-se na diferença entre o valor da média e da mediana da imagem pós-tratamento e no valor da média e de mediana na imagem pré-tratamento.

Após a normalização, foram criadas seleções de imagem que incluíam o máximo do parênquima mamário possível, excetuando-se o músculo peitoral maior. Para tanto, utilizouse o editor de imagens Adobe Photoshop ${ }^{\circledR}$, versão 6.01, da Adobe Systems Incorporated, para Windows, no ajuste e quantificação de valores das imagens radiográficas.

Foram utilizadas as ferramentas paths, que no Adobe Photoshop ${ }^{\circledR}$ são usadas para realizar seleção e definição de áreas em uma imagem. Essa parte da imagem selecionada era estudada através do software citado acima sendo gerado um histograma de níveis de cinza, que fornecia automaticamente os valores de média, mediana e desvio padrão. Esse procedimento era repetido nas grafias antes e após o uso da tibolona sendo extraídos os histogramas das regiões segmentadas do tecido mamário para comparação entre as imagens 
pré e pós-tratamento (Figura 6). As áreas das regiões segmentadas do tecido mamário também foram computadas. Tanto as regiões de tecido mamário quanto do objeto de referência foram delimitadas por médico com experiência em leitura de mamografias.

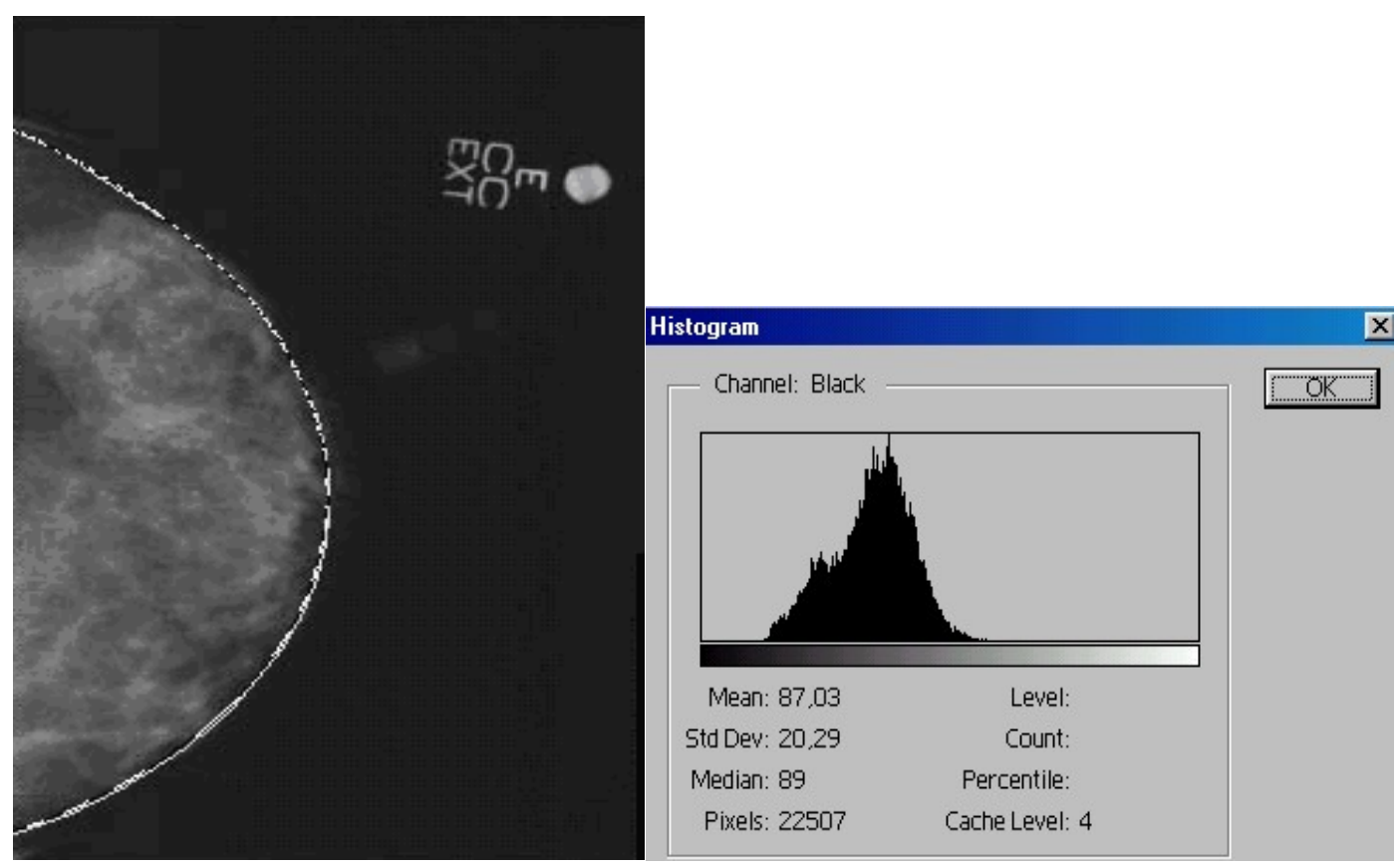

Figura 6. Avaliação da área delimitada da mama através do histograma.

\subsection{Análise Estatística}

A análise estatística da avaliação computadorizada, comparando os valores das médias e das medianas das imagens antes e após o uso de tibolona, foi realizada através do teste $\mathrm{t}$ pareado após ter sido testada a normalidade dos dados utilizando-se o teste $\mathrm{KS}$ (Kolmogorov-Smirnov). A análise estatística dos dados dos examinadores foi feita através do teste Kappa. Para essas avaliações foi usado o software Graphpad Prism, versão 3.0. 


\subsection{Redação do Texto}

A redação deste texto foi realizada conforme as normas técnicas da Associação Brasileira de Normas Técnicas, com modificações sugeridas pelo Sistema Integrado de Bibliotecas - SIBI da Universidade de São Paulo, denominado Diretrizes para Apresentação de Dissertações e Teses da USP (Universidade de São Paulo, 2004). 
5. RESULTADOS 


\subsection{Análise do Examinador 1}

Em relação à análise realizada pelo Examinador 1, duas pacientes tiveram análises da densidade mamária discordantes em relação à avaliação inicial. Houve aumento da densidade mamária em uma paciente, cujo laudo final foi compatível com mamas heterogeneamente densas, em relação à mamografia inicial, que recebeu laudo de densidade fibroglandular dispersa. Em outro caso, a discordância foi no sentido oposto, ou seja, segundo o laudo da mamografia, houve melhora da densidade entre a mamografia inicial (mamas heterogeneamente densas) e o laudo da mamografia final (densidade fibroglandular dispersa). Desta forma, de acordo com o Examinador 1, não houve variação significativa na densidade mamográfica das grafias analisadas (Tabela 1 e Figura 7).

Tabela 1. Avaliação da densidade mamográfica antes e após tratamento realizada pelo examinador 1.

\begin{tabular}{ccc}
\hline & \multicolumn{2}{c}{ NÚMERO DE CASOS } \\
\cline { 2 - 3 } & PRÉ & PÓS \\
\hline LIPOSSUBSTITUÍDA & 15 & 15 \\
DENS. FIBROGL. DISPERSA & 8 & 8 \\
HETEROGÊNEAMENTE DENSA & 3 & 3 \\
\hline
\end{tabular}




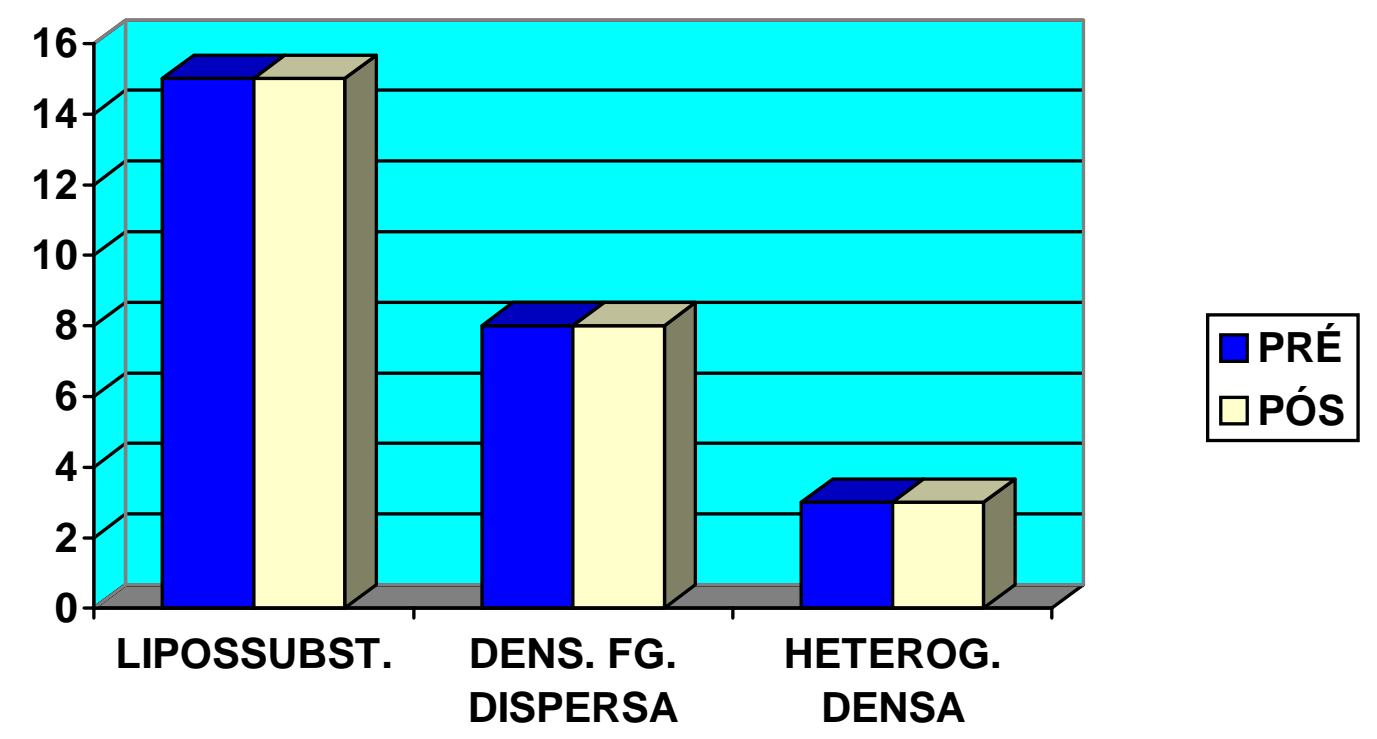

Figura 7. Análise da densidade mamográfica feita pelo Examinador 1.

\subsection{Análise do Examinador 2}

Da mesma forma, a análise feita pelo Examinador 2 mostrou uma variação de densidade mamária na mamografia pré e pós o uso da tibolona em dois casos. Nesses dois casos, houve a modificação da classificação de mamas lipossubstituídas para mamas com densidade fibroglandular dispersa. A análise estatística desses dados não foi significativa, portanto, segundo a avaliação do Examinador 2, não existiu variação na densidade mamográfica das grafias analisadas (Tabela 2 e Figura 8). 
Tabela 2. Avaliação da densidade mamográfica antes e após tratamento realizada pelo Examinador 2.

\begin{tabular}{ccc}
\hline & \multicolumn{2}{c}{ NÚMERO DE CASOS } \\
\cline { 2 - 3 } & PRÉ & PÓS \\
\hline LIPOSSUBSTITUÍDA & 6 & 4 \\
DENS. FIBROGL. DISPERSA & 17 & 19 \\
HETEROGÊNEAMENTE DENSA & 3 & 3 \\
\hline
\end{tabular}

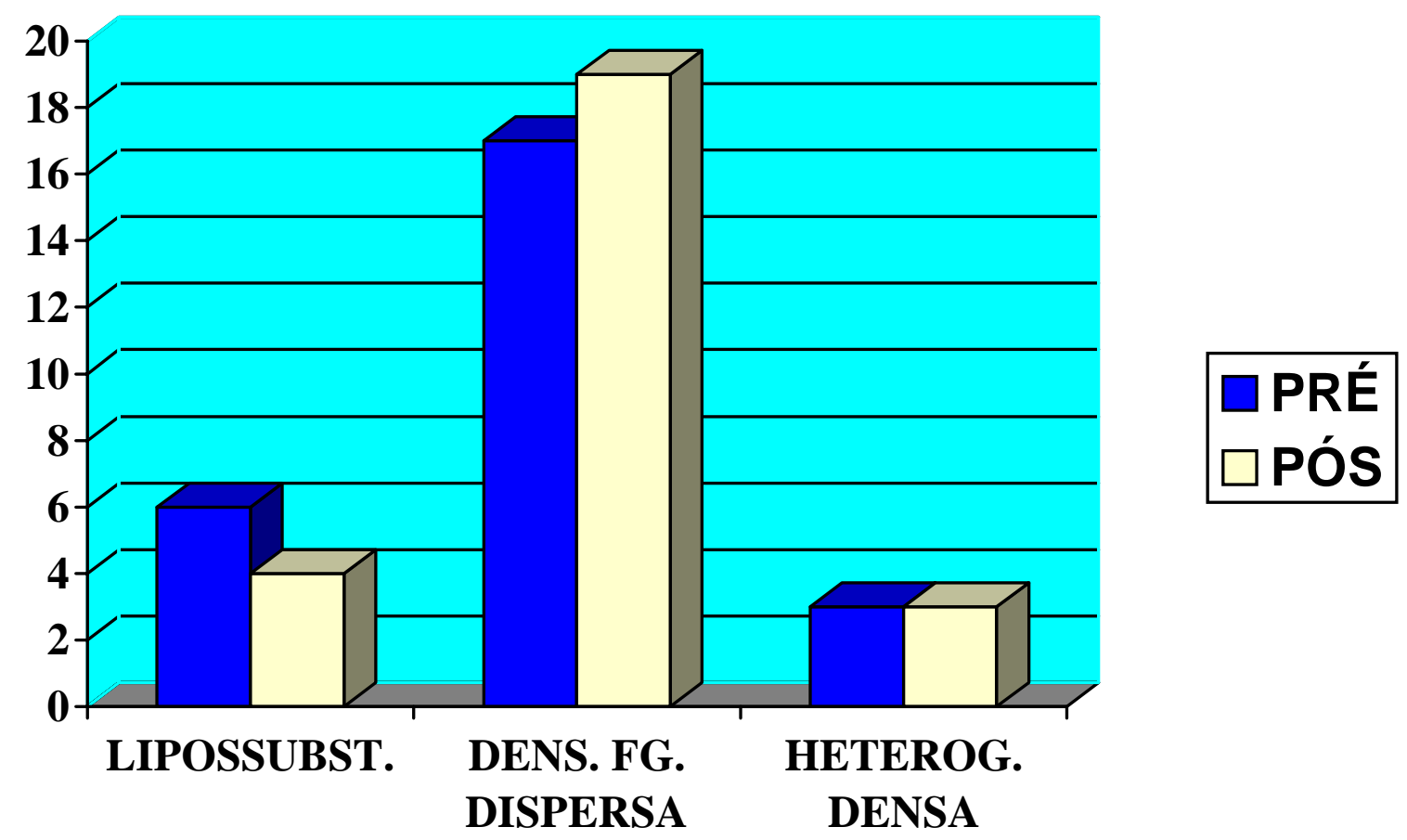

Figura 8. Análise da densidade mamográfica feitas pelo Examinador 2. 


\subsection{Análise Interexaminadores}

A comparação entre a análise dos Examinadores 1 e 2 nos mesmos estudos mamográficos (pré e pós-tratamento) demonstrou uma tendência à variabilidade interexaminador na interpretação da densidade das grafias, sendo o resultado do teste Kappa, respectivamente, de 0,433 e 0,238 para as mamografias pré e pós tratamento.

$\mathrm{Na}$ análise das grafias pré-tratamento, enquanto o Examinador Um classificou a maior parte como sendo mamas lipossubstituídas (57,7\%), o Examinador Dois classificou as mesmas grafias como sendo na sua maior parte com densidades fibroglandulares dispersas $(65,4 \%)$. Da mesma forma, na análise das grafias pós-tratamento esta variação se manteve, tendo o Examinador 1 classificado a maioria das grafias como lipossubstituídas (57,7\%), enquanto o Examinador 2 classificou a maioria como sendo de densidades fibroglandulares dispersas $(73,1 \%)$ (Tabela 3).

A análise estatística desses dados não se mostrou significativa, porém, devido às diferenças encontradas, pode-se inferir algum grau de variabilidade na análise subjetiva feita pelos Examinadores da densidade das grafias. 
Tabela 3. Comparação entre os laudos emitidos pelos Examinadores 1 e 2 na avaliação de densidade mamária à mamografia pré e pós-terapia com tibolona.

\begin{tabular}{ccccc}
\hline & \multicolumn{2}{c}{ PRÉ-TRATAMENTO } & \multicolumn{2}{l}{ PÓS-TRATAMENTO } \\
\cline { 2 - 5 } & EXAM. 1 & EXAM. 2 & EXAM. 1 & EXAM. 2 \\
\hline LIPOSSUBSTITUÍDAS & $15(57,7 \%)$ & $6(23,1 \%)$ & $15(57,7 \%)$ & $4(15,4 \%)$ \\
DENS. FIBROGL. & $8(30,8 \%)$ & $17(65,4 \%)$ & $8(30,8 \%)$ & $19(73,1 \%)$ \\
DISPERSAS & & & & \\
HETEROGENEAMENTE & $3(11,5 \%)$ & $3(11,5 \%)$ & $3(11,5 \%)$ & $3(11,5 \%)$ \\
DENSAS & & & & \\
\hline
\end{tabular}

\subsection{Análise Computadorizada da Densidade Mamográfica}

$\mathrm{Na}$ análise computadorizada da densidade mamária à mamografia, foram utilizados os valores médios e valores medianos gerados através do programa Adobe Photoshop. Esses dados passaram no teste de normalidade de Kolmogorov- Smirnov tendo distribuição normal em todos os grupos. Após o teste de normalidade, compararam-se estes valores médios e medianos dos grupos antes e após o uso de medicação.

Os valores médios e medianos dos histogramas das mamografias estão representados na figura 9. 


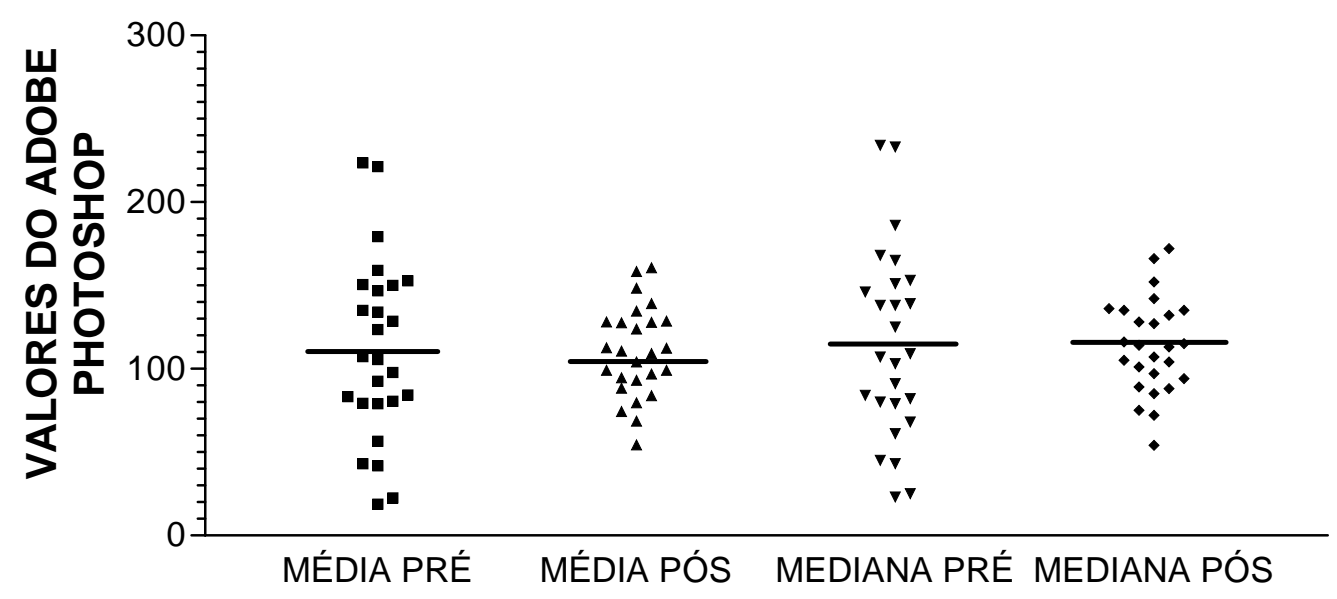

Figura 9. Distribuição dos valores médios e medianos gerados na análise computadorizada das grafias.

A média dos valores médios gerados pelos histogramas nas imagens das mamas foi 111,50 antes e 109,94 após o uso da tibolona $(\mathrm{p}=0,85)$. Da mesma forma, foram utilizadas as médias dos valores medianos gerados pelo programa Adobe Photoshop na análise das imagens mamárias, obtendo-se resultados de 114,46 antes do uso da medicação e 113,62 após o uso da medicação $(\mathrm{p}=0,92)$ (tabela 4 e figura 10). Portanto, a análise computadorizada não mostrou diferença da densidade mamográfica antes a após o uso de tibolona, estando de acordo com a avaliação dos examinadores. 
Tabela 4. Média das médias e medianas gerada pelo programa Adobe Photoshop na análise das mamografias.

\begin{tabular}{ccc}
\hline & \multicolumn{2}{c}{ MEDICAÇÃO } \\
\cline { 2 - 3 } & PRÉ & PÓS \\
\hline MÉDIA DAS MÉDIAS & 111,49 & 109,94 \\
MÉDIA DAS MEDIANAS & 114,46 & 113,61 \\
\hline p(média $)=0,85 ;$ p(mediana $)=0,92$ & \\
\hline
\end{tabular}

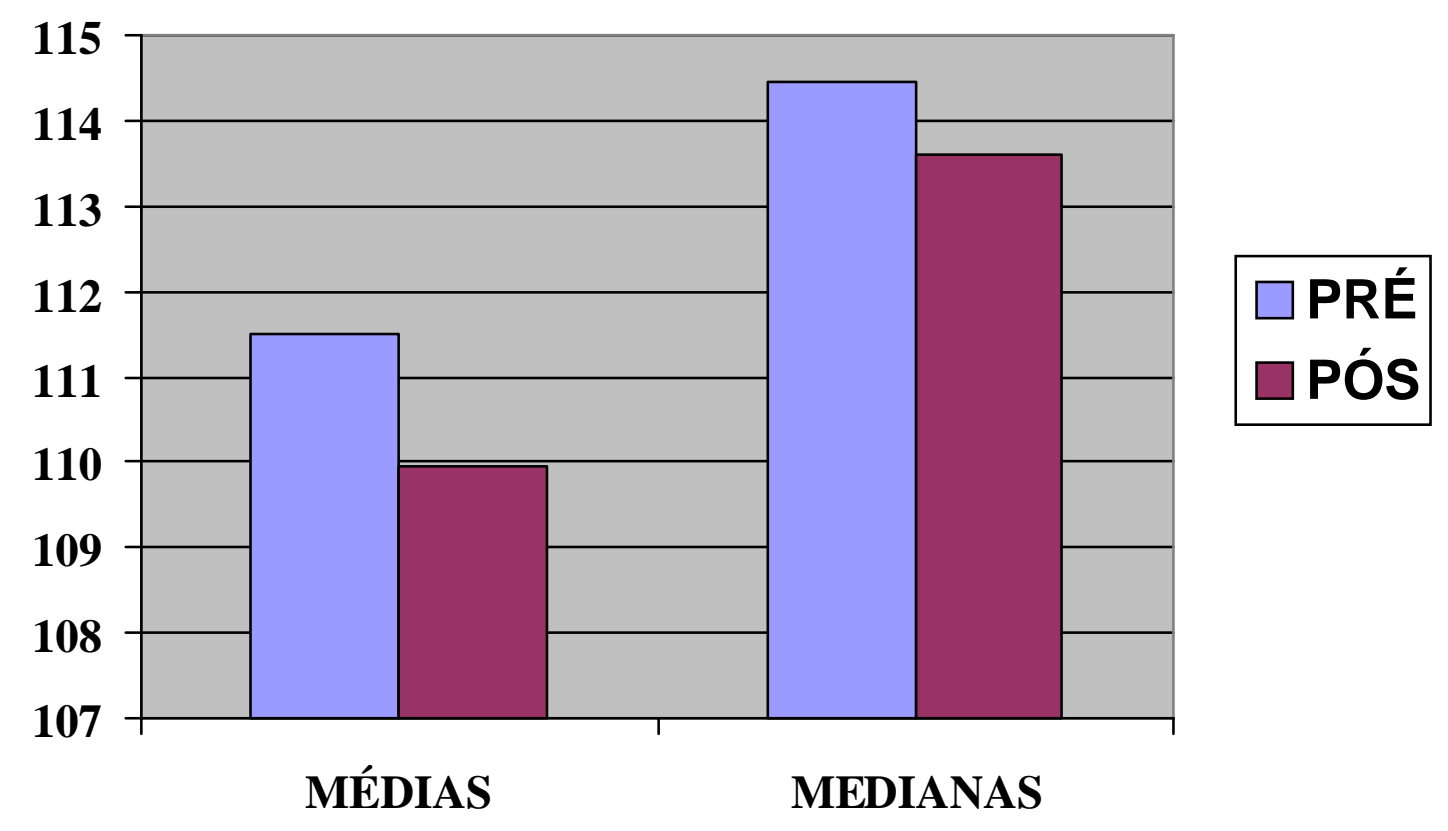

Figura 10. Média das médias e medianas geradas na análise computadorizada das mamografias. 
6. DISCUSSÃO 
A terapia hormonal na mulher climatérica já foi usada de forma mais ampla e liberal que atualmente. Ao final da década passada, vários artigos já alertavam contra possíveis riscos associados ao uso dessa terapia, realçando que diferentes formulações poderiam determinar riscos diversos (SPEROFF et al., 2005).

Somente após os intensos debates gerados com a publicação dos resultados de estudos randomizados e controlados, como o WHI (WRITING GROUP FOR THE WOMEN'S HEALTH INITIATIVE INVESTIGATORS, 2002) e o Million Women (BERAL, 2003), é que a prescrição da terapia hormonal passou a ser feita com maior critério. Vários dos efeitos tidos como benéficos decorrentes da reposição hormonal não encontraram respaldo científico nestes trabalhos e suscitaram várias controvérsias (KENNEMANS \& SPEROFF, 2005).

Atualmente, as principais indicações dos vários tipos de terapias hormonais conhecidos, restringem-se em melhorar a densidade mineral óssea e a combater os sintomas climatéricos, principalmente os fenômenos vasomotores e a atrofia urogenital. À parte destes benefícios, a reposição hormonal feita com determinados esquemas, pode desencadear efeitos indesejáveis, principalmente nas mamas, como dores, edema, sensação de nodulações e aumento da densidade na mamografia.

Para os ginecologistas em geral, talvez a conclusão que mais tenha causado impacto foi a de que essa forma de tratamento, na dependência do esquema utilizado, eleva o risco para o câncer de mama (BERAL, 2003), fato que provocou pânico entre as usuárias e mudanças na orientação da prescrição desta terapia (ETTINGER et al., 2003; GRANZIOTTIN, 2005).

Vários métodos propedêuticos são utilizados para se chegar ao diagnóstico da doença maligna da mama, preferencialmente em suas fases iniciais. 
A mamografia é o método considerado "padrão ouro" para o rastreio e detecção precoce do câncer de mama nos dias atuais. Diferentes fatores podem influenciar de forma favorável ou de forma desfavorável a eficácia do exame.

As limitações podem ser devidas a fatores inerentes ao aparelho, ao filme, à revelação e também a fatores específicos do paciente, como a densidade mamária que tem grande relevância uma vez que a acuidade desse método é inversamente proporcional à densidade da mama analisada, ou seja, quanto mais densa a mama mais difícil a avaliação da mesma (MANDELSON et al., 2000).

No exame radiológico, a maior densidade mamária pode dificultar a visualização ou até ocultar lesões iniciais sugestivas de malignidade, tornando os exames de rastreio ou diagnóstico precoce das lesões mamárias menos sensíveis (VALDIVIA et al., 2004).

Um percentual variado de mulheres tem as mamas com maior densidade durante todo o período de menacme. Estas mulheres ainda apresentam, mesmo após a menopausa, quando deveria estar ocorrendo a liposubstituição, mamas mais densas à mamografia, fato que pode ser determinado por fatores genéticos (BOYD et al., 2002). Esses fatores podem estar envolvidos com a maior incidência do câncer de mama (ZIV et al., 2003).

Por outro lado, com o advento da terapia hormonal, o aumento da densidade mamária é uma conseqüência freqüente, o que leva à observação mais rigorosa das usuárias dessa terapia, visto que a densidade aumentada da mama pode elevar o risco relativo para o câncer em até seis vezes (KENEMANS \& SPEROFF, 2005). Na terapia hormonal, os diferentes esquemas utilizados determinam diferentes variações na densidade mamária (SPEROFF et al., 2005).

Esquemas que utilizam estrógeno, com ou sem a associação de progestágeno, apresentam este efeito colateral de forma mais intensa que mulheres que utilizam a tibolona e, como conseqüência, aumentam o índice de exames falsos positivos com mulheres usuárias 
desta terapia hormonal (BANKS et al., 2005). É bem sabido que a terapia hormonal combinada, em qualquer esquema utilizado, sempre desencadeia maior densidade mamária que a terapia isolada com estrógenos ou tibolona (VALDIVIA et al., 2004). Algumas terapias hormonais classificadas como SERMS, entre elas o raloxifeno, melhoram a densidade mineral óssea e não apresentam efeitos adversos nas mamas, porém, em contrapartida, apresentam reduzida ação sobre os sintomas climatéricos.

Atualmente, a tibolona é a única forma de terapia hormonal que vem demonstrando melhora dos sintomas climatéricos com menores índices de efeitos na mama. Essa vantagem ficou bem definida a partir da observação que usuárias de tibolona apresentavam menores índices de queixas de mastodínea (COLACURCI et al., 1998).

Os mecanismos pelos quais os hormônios aumentam a densidade das mamas são controversos. Greendale et al. (1999) encontraram, em estudo com 307 participantes, aumento significativo da densidade mamográfica durante o primeiro ano de uso de estrogênios eqüinos conjugados associados ou não à progesterona. Na esteroidogênese mamária (intracrinologia), a aromatase converte a androstenediona em estrona, que é um estrogênio fraco. No tecido mamário normal, a 17beta-hidroxi-estréoide-desidrogenase tipo I (17ßHSD-tipo I) converte a estrona em estradiol, um estrogênio mais potente, enquanto a 17beta-hidroxi-estréoide-desidrogenase tipo II (17ßHSD-tipo II) faz a conversão em sentido oposto. Este mecanismo enzimático está sob controle da progesterona (KLOOSTEBOER, 2004).

A tibolona e seus metabólitos inibem a ação da enzima 17ßHSD-tipo I, induzem a ação da 17ßHSD-tipo II e da sulfotransferase, diminuindo o pool total de estrogênios no tecido mamário, inibindo a proliferação e estimulando a apoptose das células mamárias (GOMPEL et al., 2002; KLOOSTERBOER, 2004). A ação protetora da tibolona torna-se mais evidente pelo fato da concentração da estrona sulfatada estar aumentada em tecido 
mamário de mulheres menopausadas, e neste tecido a esteroidogênese se faz preferencialmente pela via da sulfatase em detrimento da aromatase (PASQUALINE, 2004). A tibolona e seus metabólitos parecem não exercer influência na atividade da aromatase (PASQUALINE et al., 1996), porém como esta via de esteroidogênese mamária é menos importante, a ausência deste eventual efeito protetor tem relevância reduzida.

Outro estudo que ressalta a ação protetora da tibolona sobre a mama quando comparada com outra forma de terapia hormonal combinada em que se utilizou estrogênio eqüino conjugado e acetato de medroxiprogesterona, demonstrou, de forma bastante clara, que após um ano de terapia com tibolona, ocorreu redução do índice de proliferação celular, aumento da apoptose e diminuição da densidade mamária. Por outro lado, a terapia hormonal combinada com estrogênio e medroxiprogesterona provocou aumento da taxa de proliferação celular e inibição da taxa de apoptose, com conseqüente aumento da densidade mamária (VALDIVIA et al., 2004).

Corroborando esse estudo, Pantidou et al. (2004) publicaram trabalho envolvendo 83 pacientes que usaram tibolona por um período variável de seis meses a cinco anos e descreveram não ter encontrado diferenças significativas na densidade dos mamogramas antes e após o uso dessa droga.

Na tentativa de confirmar a relação entre a densidade mamária e a presença de tecido epitelial, Hawes et al. (2006) realizaram estudo de peças cirúrgicas provenientes de mastoplastia reducional. Nesse estudo, mostraram haver relação direta entre as áreas de maior densidade mamária e a maior concentração de tecido epitelial (unidades terminais ducto-alveolar), e que, esta maior densidade está também diretamente relacionada ao aumento da quantidade de colágeno.

Mais recentemente, outras hipóteses sugerem a participação, de forma importante, do estroma mamário na densidade mamográfica, o que é lógico, pois o estroma representa o 
principal componente da mama. Realça sua importância o fato de ele ser sede de alterações genéticas, que proporcionam um micro-ambiente adequado à evolução tumoral (MOINFAR et al., 2000).

Estudos recentes mostram que o estroma mamário é rico em proteoglicanos, principalmente aqueles que atuam, tanto na preservação da integridade do estroma, quanto na interação com fatores de crescimento. Dentre esses podemos citar o estudo de Alowami et al. (2003) em que ficou demonstrado que proteoglicanos ricos em leucinas, decorina e lumicana são encontrados em regiões ricas em colágeno e essas são vistas como áreas densas na mamografia. Nesse estudo, áreas de maior densidade mamográfica foram biopsiadas e mostraram quantidade três vezes maior de colágeno que áreas de menor densidade mamária. Esses autores também demonstraram, no mesmo estudo, a maior incidência de carcinoma in situ em área de maior densidade, devido ao estroma mais rico em colágeno.

Em outro estudo, ficou demonstrado que áreas densas na mamografia também possuem concentração duas vezes maior de fator de crescimento insulínico I (IGF-I) que nas áreas de menor densidade (GUO et al., 2001). Sabe-se que a IGF-I é regulada positivamente pelos estrógenos, daí a maior densidade mamária resultar em maior risco para o câncer de mama.

Assim, parece inequívoco que a densidade mamária aumentada está diretamente relacionada ao maior risco de câncer de mama.

A avaliação da densidade mamográfica é feita, nos dias de hoje, de um modo subjetivo denominado Breast Imaging Reporting and Data System (BI-RADS) proposto pelo Colégio Americano de Radiologia em que o examinador classifica as mamas de acordo com a densidade de forma descritiva em: I - predominantemente lipossubstituídas, II - densidades fibroglandulares dispersas, III - mamas heterogeneamente densas, IV - mamas extremamente densas (AMERICAN COLLEGE OF RADIOLOGY, 1998). Esse padrão pode receber 
críticas, uma vez que a opinião em relação à densidade mamográfica pode variar de acordo com o examinador, entretanto foi uma importante tentativa de padronização dos laudos mamográficos e de condutas indicadas na avaliação das grafias mamárias.

Partindo dessa informação, existe uma busca contínua em duas direções. Por um lado, tenta-se descobrir um método melhor que a mamografia para detectar lesões mamárias e, por outro, avaliar o grau de confiabilidade desse exame.

O primeiro estudo em que se demonstrou uma preocupação com a interferência humana na análise da densidade mamográfica foi publicado em 2006. Nesse estudo os autores utilizaram imagens digitalizadas de mamografias realizadas antes e após o uso de raloxifeno. As mamografias foram digitalizadas através de scanner Vidar VXR-12. Foram realizadas as delimitações das áreas de interesse correspondentes às imagens geradas pelas mamas nas grafias. Posteriormente à normalização das imagens das áreas de interesse através de comparação com outras áreas da mama, a imagem da área de interesse foi submetida a uma análise computadorizada em níveis de cinza através de software comercial (LASCO et al, 2006).

Em nosso estudo utilizamos também um método de análise computadorizada para determinar as variações da densidade mamográfica, porém o fizemos antes e após o uso de tibolona. O método de análise computadorizada utilizada em nosso estudo foi semelhante ao estudo realizado por Lasco e colaboradores. Para digitalização das imagens também utilizamos um scanner da marca Vidar. A área de cada mamograma correspondente à mama também foi delimitada. Diferentemente do estudo acima, para evitar possíveis variações decorrentes da técnica de realização das grafias, usamos para a normalização, a imagem de um artefato de acrílico colocado com esse objetivo durante a realização do exame. Em seguida, foi realizada a análise da densidade da área de interesse previamente delimitada em níveis de cinza através de software comercial. 
Para validação da técnica computadorizada de análise da densidade mamográfica, comparamos os resultados da análise computadorizada com o método tradicional de classificação da densidade mamária proposto pelo Colégio Americano de Radiologia (BIRADS). A análise foi realizada por dois examinadores, não sendo encontradas diferenças importantes entre eles e em relação à análise computadorizada.

A grande vantagem da análise da densidade mamográfica pelo computador é poder ser utilizada como método auxiliar eficaz na avaliação da densidade mamográfica e, portanto, passível de ser utilizado para quantificar a densidade mamográfica e a possibilidade de ocultação de alguma alteração pelo parênquima mamário normal.

Alguns avanços em termos de análise das imagens mamográficas vêm sendo implantados no decorrer dos últimos anos, através da implantação da revelação computadorizada das grafias obtendo-se melhor qualidade de imagem e, conseqüentemente, maior facilidade de leitura.

O advento da mamografia digital causou grande impacto no meio médico devido a sua capacidade de permitir a avaliação de detalhes, recurso obtido através de ampliação das imagens capturadas e das modificações de níveis de brilho e contraste, apresentando, portanto, maior sensibilidade em relação à mamografia tradicional. Apesar de todas estas vantagens, esse exame não se difundiu por dificuldades financeiras e técnicas.

Paralelamente ao refinamento das técnicas de mamografia, vêm-se tentando utilizar outros exames para screening de lesões mamárias, sendo essas a ultra-sonografia, a ressonância magnética, a tomografia computadorizada e até a termografia; contudo, essas apresentam limitações importantes, como custos e dificuldades de treinamento de pessoal.

Portanto, devido à necessidade de terapias para manter a qualidade de vida de uma população cada vez mais idosa e ao aumento da incidência de câncer de mama, tende-se 
seguir rumo ao refinamento de exames de diagnóstico e ao advento de novas drogas com menos efeitos mamários. 


\section{CONCLUSÕES}


A tibolona, se usada em pacientes na pós-menopausa, na dosagem de $2,5 \mathrm{mg} / \mathrm{dia}$ por um período de 24 semanas, não altera a densidade mamográfica e, conseqüentemente, não altera a acuidade do exame.

Em nosso estudo, a tibolona foi praticamente desprovida de efeitos mamários e, portanto, deve ser considerada como uma boa opção de terapia hormonal para pacientes com queixas mamárias.

A análise da densidade mamográfica pode ser realizada de forma computadorizada sem maiores dificuldades técnicas e com segurança. A análise computadorizada da densidade das mamografias pode se constituir em importante auxílio aos radiologistas, nos casos onde a densidade mamária dificulta a avaliação rotineira. 
8. REFERÊNCIAS BIBLIOGRÁFICAS 
AMERICAN COLLEGE OF RADIOLOGY. Breast Imaging Reporting and Data System. BI-RADS $^{\text {TM }}$. 3rd ed. Reston, VA: ACR, 1998.

ALOWAMI, S.; TROUP, S.; AL-HADDAD, S.; KIRKPATRICK, I.; WATSON, P.H. Mammographic density is related to stroma and stromal proteoglycan expression. Breast Cancer Res, 5: 129-35, 2003.

BACHMANN, G.A. - Vulvovaginal complaints. In: - Lobo, R.A. Treatment of the postmenopausal Woman: Basic and Clinical aspects. Raven Press, 1994. p. 140.

BAERUG, U.; WINGE, T.; NORDLAND, G.; FABER-SWENSSON, E.; HELDAAS, K.; NORLING, B.; LARSEN, S.; ARCE, J.C. Do combinations of 1 mg estradiol and low doses of NETA effectively control menopausal symptoms? Climacteric, 1: 219-28, 1998.

BAGNOLI, V.R.; FONSECA, A.M.; ASSIS, J.S.; ROSAS, F.C.; PINOTTI, J.A. Terapia de Reposição Hormonal: Esquemas. In: - Terapia de Reposição Hormonal em Situações Especiais. Editora Revinter, 2001.p. 01-5.

BANKS, E.; REEVES, G.; BERAL. V.; BULL, D.; CROSSLEY, B.; SIMMONDS, M.; HILTON, E.; BAILEY, S.; BARRETT, N.; BRIERS, P.; ENGLISH, R.; JACKSON, A.; KUTT, E.; LAVELlE, J.; ROCKALL, L.; WALliS, M.G.; WILSON, M.; PATNICK, J. Hormone replacement therapy and false positive recall in the million women study: patterns of use, hormonal constituents and consistency of effect. Breast Cancer Res, 8: R8 (1-9), 2005. 
BERAL, V. Breast cancer and hormone-replacement therapy in the million women study. Lancet, 362: 419-27, 2003.

BERAL, V.; BULL, D.; REEVES, G. Endometrial cancer and hormone-replacement therapy in the million women study. Lancet, 365: 1543-51, 2005.

BERG, W.A.; CAMPASSI, C.; LANGENBERG, P.; SEXTON, M.J. Breast imaging reporting and data system: Inter- and intraobserver variability in feature analysis and final assessment. AJR Am J Roentgenol, 174: 1769-77, 2000.

BIRGE, S.J. The role of estrogen in treatment of alzheimer's disease. Neurology, 48: 36, 1997.

BONNIER, P.; SAKR, R.; BESSENAY, F.; LEJEUNE, C.; CHARPIN, C.; MARTIN, P.M.; PIANA, L. Effects of hormone replacement therapy for menopause on prognostic factors of breast cancer. Gynecol Obstet Fertil, 28: 745-53, 2000.

BOYD, N.F.; DITE, G.S.; STONE, J. Heritability of mammographic density, a risk factor for breast cancer. N Engl J Med, 347: 886-94, 2002.

BÜLBÜL, N.H.; OZDEN, S.; DAYICIOGLU, V. Effects of hormone replacement therapy on mammografic findings. Arch Gynecol Obstet, 268: 5-8, 2003. 
BYRNE, C.; SCHAIRER, C.; WOLFE, J.; PAREKH, N.; SALANE, M.; BRINTON, L.A.; HOOVER, R.; HAILE, R. Mammographic features and breast cancer risk: effects with time, age, and menopause status. J Natl Cancer Inst, 87: 1622-9, 1995.

CHIECHI, L.M.; SECRETO, G. Factors of risk for breast cancer influencing postmenopausal long-term hormone replacement therapy. Tumori, 86: 12-6, 2000.

CHRISTODOULAKOS, G.E.; LAMBRINOUDAKI, I.V.; VOURTSI, A.D.; PANOULIS, K.P.; KELEKIS, D.A.; CREATSAS, G.C. Mammographic changes associated with raloxifene and tibolone therapy in postmenopausal women: A prospective study. Menopause, 9: 110-6, 2002.

COBLEIGH, M.A.; NORLOCK, F.E.; OLESKE, D.M.; STARR, A. Context prolonged postmenopausal hormone replacement therapy (HRT) is associated with increased incidence of breast cancer and, paradoxically, reduced breast cancer mortality. The biological rationale for this discrepancy has not been explored. JAMA, 281: 1528-30, 1999.

COLACURCI, N.; MELE, D.; DE FRANCISCIS, P.; COSTA, V.; FORTUNATO, N.; DE SETA, L. Effects of tibolone on the breast. Eur J Obstet Gynecol Reprod Biol, 80: 235-8, 1998.

COLACURCI, N.; FORNARO, F.; DE FRANCISCIS, P.; PALERMO, M.; DEL VECCHIO, W. Effects of different type of hormone replacement therapy on mammographic density. Maturitas, 40: 159-64, 2001. 
COLDITZ, G.A.; HANKINSON, S.E.; HUNTER, D.J.; WILLETT, W.C.; MANSON, J.E.; STAMPFER, M.J.; HENNEKENS, C.; ROSNER, B.; SPEIZER, F.E. The use of estrogens and progestins and the risk of breast cancer in postmenopausal women. $\mathrm{N}$ Engl $\mathrm{J}$ Med, 332: 1589-93, 1995.

COLLABORATIVE GROUP ON HORMONAL FACTORS IN BREAST CANCER. Breast cancer and hormone replacement therapy: Collaborative reanalysis of data from 51 epidemiological studies of 52.705 women with breast cancer and $\mathbf{1 0 8 . 4 1 1}$ women without breast cancer [publishied erratum appears in Lancet 1997; 350:1484 ]. Lancet, 350: 1047-59, 1997.

DELMAS, P.D.; CONFAVREUX, E.; GARNERO, P.; FARDELLONE, P.; DE VERNEJOUL, M.C.; CORMIER, C.; ARCE, J.C. A combination of low doses of 17 betaestradiol and norethisterone acetate prevents bone loss and normalizes bone turnover in postmenopausal women. Osteoporos Int, 11:177-87, 2000.

DIMITRAKAKIS, C.; KERAMOPOULOS, D.; VOURLI, G.; GAKI, V.; BREDAKIS, N.; KERAMOPOULOS, A. Clinical effects of tibolone in postmenopausal women after 5 years of tamoxifen therapy for breast cancer. Climacteric, 8: 342-51, 2005.

EGARTER, C.; HUBER,J.; LEIKERMOSER, R.; HAIDBAUER, R.; PUSCH, H.; FISCHL, F.; PUTZ, M. Tibolone versus conjugated estrogens and sequential progestogen in the treatment of climateric complaints. Maturitas, 23: 55-62, 1996. 
EGARTER, C.; EPPEL, W.; VOGEL, S.; WOLF, G. A pilot study of hormone replacement therapy with tibolone in women with mastopathic breasts. Maturitas, 40: 165-71, 2001.

EREL, C.T.; ESEN, G.; SEYISOGLU, H.; EITER, K.; URAS, C.; ERTUNGEALP, E.; AKSU, M.F. Mammographic density increase in women receiving different hormone replacement regimens. Maturitas, 40: 151-7, 2001.

ETTINGER, B.; GRADY, D.; TOSTESON, A.N.; PRESSMAN, A.; MACER, J.L. Effect of the Women's Health Initiative on women's decisions to discontinue postmenopausal hormone therapy. Obstet Gynecol, 102: 1225-32, 2003.

FAJARDO, L.L.; HILLMAN, B.J.; FREY, C. Correlation between breast parenchymal patterns and mammographers'certainty of diagnosis. Invest. Radiol., 23: 505-8, 1988.

FONSECA, A.M.; MASSABKI, J.O.P.; BAGNOLI, V.R.; DIEGOLI, M.S.C. Terapia de Reposição Hormonal: Idosas. In: - Terapia de Reposição Hormonal em Situações Especiais. Editora Revinter, 2001. p. 47-52.

GOMPEL, A.; CHAOUAT, M.; JACOB, D.; PERROT, J.Y.; KLOOSTERBOER, H.J.; ROSTENE, W. In Vitro Studies of Tibolone in Breast Cells. Fertil Steril, 78: 351-9, 2002.

GRAZIOTTIN, A. The womam patient after WHI. Maturitas, 51: 29-37, 2005. 
GREENDALE, G.A.; REBOUSSIN, B.A.; SIE, A.; SINGH, H.R.; OLSON, L.K.; GATEWOOD, O.; BASSETT, L.W.; WASILAUSKAS, C.; BUSH, T.; BARRETTCONNOR, E. Effects of estrogen and estrogen-progestin on mammographic parenchymal density. Postmenopausal Estrogen/Progestin Interventions (PEPI) Investigators. Ann Intern Med, 130: 262-9, 1999.

GREENE, R.A. Estrogen and cerebral blood flow: a mechanism to explain the impact of estrogen on the incidence and treatment of Alzheimer's disease. Int J Fertil Womens Med, 45: 253-7, 2000.

GUO, Y.P.; MARTIN, L.J.; HANNA, W.; BANERJEE, D.; MILLER, N.; FISHELL, E.; KHOKHA, R.; BOYD, N.F. Growth factors and stromal matrix proteins associated with mammographic densities. Cancer Epidemiol Biomarkers, 10: 243-8, 2001.

HAMMAR, M.; CHRISTAU, S.; NATHORST-BOOS, J.; RUD, T.; GARRE, K. A doubleblind, randomised trial comparing the effects of tibolone and continuous combined hormone replacement therapy in postmenopausal women with menopausal symptoms. Br J Obstet Gynaecol, 105: 904-11, 1998.

HAWES, D.; DOWNEY, S.; PEARCE, C.L.; BARTOW, S.; WAN, P.; PIKE, M.C.; WU, A.H. Dense breast stromal tissue shows greatly increased concentration of breast epithelium but no increase in its proliferative activity. Breast Cancer Res, 8: 24-5, 2006. 
HENDERSON, S.W.; PAGANINI-HILL, A.; EMANUEL, C.K.; DUNN, M.E.; BUCKWALTER, J.G. Estrogen replacement therapy in older women. Arch Neurol, 5: 856, 1994.

HEYWANG-KÖBRUNNER, S.H.; SCHREER, I.; DERSHAW, D.D.; FRASSON, A. Mamografia In: - Mama, diagnóstico por imagem. Editora Revinter, 1999. p. 11-80.

HOLLI, K.; ISOLA, J.; CUZICK, J. Low biologic aggressiveness in breast cancer in women using hormone replacement therapy. J Clin Oncol, 16: 3115-20, 1998.

HOMER, M.J. Breast imaging: pitfalls, controversies, and some practical thoughts. Radiol Clin North Am, 23: 459-72, 1985.

IMTHURN, B.; MAURER-MAJOR, E. Climacteric syndrome. Ther Umsch, 57: 595-9, 2000.

JACKSON, V.P.; HENDRICK R.E.; FEIG, S.A.; KOPANS, D.B. Imaging of the radiographically dense breast. Radiology, 188: 297-301, 1993.

JAMIN, C.; BOURG, F.; LEGEAI, J.; SENOUSSI, S. Is the clinical profile of women treated with tibolone similar to that of women receiving a classical estrogenprogestogen therapy? Data from a nationwide survey in France. Gynecol Obstet Fértil, 34: 224-32, 2006. 
KAUFMAN, Z.; GARSTIN, W.I.; HAYES, R.; MICHELL, M.J.; BAUM, M. The mammographic parenchymal patterns of women on hormone replacement therapy. Clin Radiol, 43: 389-92, 1991.

KENEMANS, P.; SPEROFF, L. Tibolone: Clinical recommendations and practical guidelines. A report of the International Tibolone Consensus Group. Maturitas, 51: 21-28, 2005.

KERLIKOWSKE, K.; GRADY, D.; BARCLAY, J.; FRANKEL, S.D.; OMINSKY, S.H.; SICKLES, E.A.; ERNSTER, V. Variability and accuracy in mammographic interpretation using the American College of Radiology Breast Imaging Reporting and Data System. J. Natl. Cancer Inst., 90: 1801-9, 1998.

KLAIBER, E.L.; VOGEL, W.; RALCO, S. A critique of the Women's Health Initiative hormone therapy study. Fertility and Sterility, 84:1589-601,2005.

KLOOSTERBOER, H.J. Tissue-selectivity: The mechanism of action of tibolone. Maturitas, 48: 30-40, 2004.

KLOOSTERBOER, H.J. Tissue-selective effects of tibolona on the breast. Maturitas, 49: $5-15,2004$. 
LASCO, A.; GAUDIO, A.; MORINI, E.; MORBITO, N.; NICITA-MAURO, C.; CATALANO, A.; DENUZZO, G.; SANSOTTA, C.; XOURAFA, A.; MACRI, I.; FRISINA, N. Effect of long-term treatment with raloxifene on mammary density in postmenopausal women. Menopause, 13: 787-92, 2006.

LEUNG, W.; GOLDBERG, F.; ZEE, B.; STERNS, E. Mammographic density in women on postmenopausal hormone replacement therapy. Surgery, 122: 669-73, 1997.

LIPPUNER, K.; HAENGGI, W.; BIRKHAEUSER, M.H.; CASEZ, J.P.; JAEGER, P. Prevention of postmenopausal bone loss using tibolone or conventional peroral therapy with 17beta-estradiol and dydrogesterone. J Bone Miner Res, 12: 806-12, 1997.

LOBO, R.A. Cardiovascular implications of estrogen replacementtherapy. Obstet Gynecol, 75: 18-25, 1990.

LOBO, R.A.; BUSH, T.; CARR, B.R.; PICKAR, J.H. Effects of lowerf doses of conjugated equine estrogens and medroxyprogesterone acetate on plasma lipids and lipoproteins, coagulations factors, and carbohydrate metabolism. Fertil Steril, 76: 13-24, 2001.

LUNDSTRÖM, E.; CHRISTOW, A.; KERSEMAEKERS, W.; SVANE, G.; AZAVEDO, E.; SÖDERQVIST, G.; MOL-ARTS, M.; BARKFELDT, J.; VON SCHOULTZ, B. Effects of tibolone and continuous combined hormone replacement therapy on mammographic breast density. Am J Obstet Gynecol, 186: 717-22, 2002 
MANDELSON, M.T.; OESTREICHER, N.; PORTER, P.L.; WHITE, D.; FINDER, C.A.; TAPLIN, S.H.; WHITE, E. Breast density as a predictor of mammographic detection: comparison of interval- and screen-detected cancers. J Natl Cancer Inst, 92: 1081-7, 2000.

MAUDELONDE, T.; BROUILLET, J.P.; PUJOL, P. Anti-estrogens, selective estrogen receptor modulators (SERM), tibolone: modes of action. Contracept Fertil Sex, 27: 620-4, 1999.

MAYER, M.E. Hormone replacement and breast cancer: implications of the Iowa Women's Health Study. Cleve Clin J Med, 66: 608-10, 613, 1999.

MOINFAR, F.; MAN, Y.G.; ARNOULD, L.; BRATTHAUER, G.L.; RATSCHEK, M.; TAVASSOLI, F.A. Concurrent and independent genetic alterations in the stromal and epithelial cells of mammary carcinoma: Implications for tumorigenesis. Cancer Res, 60: 2562-6, 2000.

NETO, J.N.; DE LUCA, L.A.L.; NAHAS, E.A.P.; TRAIMAN, P.; UEMURA, G. Ação da Tibolona na Mama: Uma Revisão. Femina, 29: 221-4, 2001.

NOTELOVITZ, M.; MATTOX, J.H. Supression of vasomotor and urogenital symptoms with continuous oral 17beta-estradiol. Menopause, 7: 310-7, 2000. 
OZDEMIR, A.; KONU S, O.; NAS, T.; ERBA S, G.; CO SAR, S.; I SIK, S. Mammographic and ultrassonographic study of changes in the breast related to HRT. Int J Gynaecol Obstet, 67: 23-32, 1999.

PALACIOS, S. Climaterio: Modificaciones lipidicas y riesgo cardiovascular. Climaterio y Menopausia, 3: 147-65, 1993.

PALACIOS, S. Tibolone: what does tissue specific activity mean? Maturitas, 37: 159-65, 2001.

PAGE, D.L. \& WINFIELD, A.C. The dense mammogram. AJR Am J Roentgenol, 147: 487-9, 1986.

PANTIDOU, A.; KAPLANIS, K.; CHRISSOGONIDIS, I.; DESTOUNI, C. Mammographic changes during postmenopausal hormonal replacement therapy with tibolone. Eur J Gynaecol Oncol, 25: 493-4, 2004.

PASQUALETTE, H.A. História da mamografia, indicações e técnicas de interpretação. In: PASQUALETTE, H.A.; KOCH, H.A.; SOARES-PEREIRA, P.M.; KEMP, C. (Eds.) Mamografia Atual. Editora Revinter, 1998. p. 17-29.

PASQUALINI, J.R.; CHETRITE, G.; BLACKER, C.; FEINSTEIN, M.C.; DELALONDE, L.; TALBI, M.; MALOCHE, C. Concentrations of estrone, estradiol, and estrone sulfate and evaluation of sulfatase and aromatase activities in pre- and postmenopausal breast cancer. J Clin Endocrinol Metab, 81: 1460-4, 1996. 
PASQUALINI, J.R. The selective estrogen enzyme modulators in breast cancer: A review. Biochimica et Biophysica Acta, 1654: 123-43, 2004.

PERSSON, I.; ADAMI, H.O.; BERGKVIST, L.; LINDGREN, A.; PETTERSSON, B.; HOOVER, R.; SCHAIRER, C. Risk of endometrial cancer after treatment with oestrogens alone or in conjunction with progetogens: results of a prospective study. B.M.J., 298: 147-51, 1989.

WRITING GROUP FOR THE WOMEN'S HEALTH INITIATIVE INVESTIGATORS. Risks and benefits of estrogen plus progestin in healthy postmenopausal women: Principal results from the Women's Health Initiative randomized controlled trial. JAMA, 288(3): 321-33, 2002.

ROUX, C.; PELISSIER, C.; FECHTENBAUM, J.; LOISEAU-PERES, S.; BENHAMOU, C.L. Randomized, double-masked, 2-year comparison of tibolone with 17beta-estradiol and norethindrone acetate in preventing postmenopausal bone loss. Osteoporos Int, 13: $241-8,2002$.

SACK, M.N.; RADER, D.J.; CANNON, R.O. Oestrogen and inhibition of oxidation of low-density lipoproteins in postmenopausal women. Lancet, 343: 269-70, 1994.

SARREL, P.M.; LUFKIN, E.G.; OURSLER, M.J.; KEEFE, D. Estrogens actions in arteries, bone, and brain. Scientific American Science \& Medicine, 48: jul/ago, 1994. 
SENDAG, F.; COSAN TEREK, M.; OZSENER, S.; OZTEKIN, K.; BILGIN, O.; BILGEN, I.; MEMIS, A. Mammographic density changes during different postmenopausal hormone replacement therapies. Fertil Steril, 76: 445-50,2001.

SPEROFF, L.; GLASS, R.H.; KASE, N.G. - Menopausa e Terapia Hormonal Pósmenopausa. In: Endocrinologia Ginecológica Clínica e Infertilidade. $5^{\circ} \mathrm{ed}$. Editora Manole, 1995. p. 611-80.

SPEROFF, L.; KENEMANS, P.; BURGER, H.G. Practical guidelines for postmenopausal hormone therapy. Maturitas, 51: 4-7, 2005.

SQUITIERI, R.; TARTTER, P.I.; AHMED, S.; BROWER, S.T.; THEISE, N.D. Carcinoma of the breast in postmenopausal hormone user and nonuser. J Am Coll Surg, 178: 167$70,1994$.

STENVENSON, J.C. The metabolic and cardiovascular consequences of hormonal reposition therapy. Br J Clin Pract, 49: 87-90, 1995.

STRITMATTER, W.J.; SAUNDERS, A.M.; SCHMECHEL, D. Apolipoprotein E: Highavidity binding to $\mathrm{b}$ amyloid and increase frequency of type 4 allele in late-onset familial Alzheimer disease. Proc Natl Acad Sci USA, 90: 1977, 1993.

STUDD, J.; ARNALA, I.; KICOVIC, P.M.; ZAMBLERA, D.; KROGER, H.; HOLLAND, N. A randomized study of tibolone on bone mineral density in osteoporotic postmenopausal women with previous fractures. Obstet Gynecol, 92: 574-9, 1998. 
VALDIVIA, I.; NICO, I.C.; TAPIA, A.; CAPETILLO, M.; ESPINOZA, A.; LAVI’N, P. Effects of tibolone and continuous combined hormone therapy on mammographic breast density and breast histochemical markers in postmenopausal women. Fertil Steril, 81: 617-23, 2004.

van GILS, C.H.; HENDRIKS, J.H.; HOLLAND, R.; KARSSEMEIJER, N.; OTTEN, J.D.; STRAATMAN, H.; VERBEEK, A.L. Changes in mammographic breast density and concomitant changes in breast cancer risk. Eur. J. Cancer Prev., 8: 509-15, 1999.

VANHOECKE, B.W.; BRACKE, M.E.; KLOOSTERBOER, H.J.; DEPYPERE, H.T. Tibolone and its metabolites inhibit invasion of human mammary carcinoma cells in vitro. Maturitas, 54: 229-37, 2006.

von HOLST T Alternatives to hormonereplacement therapy: raloxifene and tibolone. $\mathrm{Z}$ Arztl Fortbild Qualitatssich, 94: 205-9, 2000.

WILLIANS, J.K. Estrogen modulates responses of athersclerotic coronary arteries. Circulation, 81: 1680-7, 1990.

WISEMAN, H.; O’REILLY, J. Oestrogen as antioxidant cardioproctants. Biochem Soc Transactions, 1997

WOLFE, J.N.; SAFTLAS, A.F.; SALANE, M. Mammographic parenchymal patterns and quantitative evaluation of mammographic densities: a case-control study. AJR Am J Roentgenol, 148: 1087-92, 1987. 
ZIV, E.; SHEPHERD, J.; SMITH-BINDMAN, R.; KERLIKOWSKE, K. Mammographic breast density and family history of breast cancer. J Natl Cancer Inst, 95: 556-8, 2003. 
ANEXOS 
Anexo 1

HOSPITAL DAS CLÍNICAS DA FACULDADE DE MEDICINA DE RIBEIRÃO PRETO - UNIVERSIDADE DE SÃO PAULO.

PROJETO: AVALIAÇÃO DA DENSIDADE MAMOGRÁFICA ANTES E APÓS TERAPIA DE REPOSIÇÃO HORMONAL

Nome:

RG:

Pcte $\mathbf{n}^{\circ}$

Idade:

Raça:

Nat.:

Proced.: Prof.:

End.:

Tel.: Tel. Rec.:

Queixas: ( ) fogachos ( ) ressecamento vaginal ( ) IUE

( ) ansiedade/depressão ( ) insônia

( ) dores ósseas ( ) mastalgia ( ) nodulação mamária

( ) outros

\section{Antecedentes familiares:}

( ) Ca de mama

( ) Outros tumores

\section{Antecedentes Pessoais:}

Doenças:

Cirurgias:

Medicação em uso:

Tabagismo: Etilismo:

Outros: 


\section{Antecedentes Mamários:}

Telarca:

Mamoplastia:

Amamentação:

Complicações da amamentação:

Repercussões menstruais:

Outros:

\section{Antecedentes Obstétricos:}

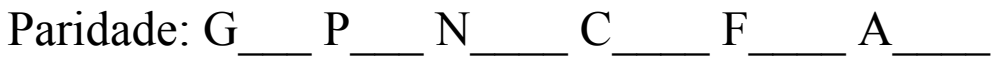

Idade da primeira gestação: ( )Parto

Aborto

Medicações hormonais /

tempo:

Antecedentes Menstruais:

Menarca Menopausa

Exame Clínico:

Peso: Alt: IMC:

PA: X

\section{Mamas:}

Inspeção Estática:

Inspeção dinâmica:

Palpação das mamas:

Direita

Esquerda

Axila/FSC

Expressão 


\section{Exames Complementares}

- Citologia Oncótica:

- Colesterol Total: HDL: TG: Glicemia: FSH: LH: PRL: _ TSH

- Outros:

- US Transvaginal:

- Densiometria Óssea:

\section{Mamografia simples bilateral:}

Primeiro Exame: Número do exame: Data:

Incidência digitalizada:

Tecn. Utilizada( KV/Mas):

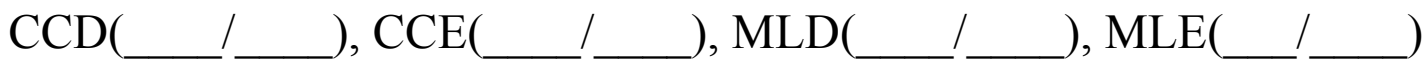

Laudo:

Filme:

Resultados da Digitalização:

Média:

Mediana:

Desvio Padrão:

Observações: 
Segundo Exame: Número do exame:

Data:

Incidência digitalizada:

Tecn. utilizada( KV/Mas):

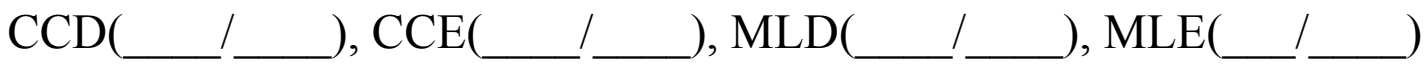

Laudo:

Filme:

Resultados da Digitalização:

Média: Mediana:

Desvio Padrão:

Observações: 
Anexo 2

\section{Exames a serem feitos em mulheres acima de 40 anos}

\section{Mamografia:}

- 40 a 50 anos: Bienal. Fazer exame anual quando paciente for de risco para Ca de mama;

- $\quad 50$ anos: Anual

Não há consenso quanto a idade de parada do exame, mas o INCA e as recomendações do consenso americano sugerem 70 anos.

\section{Interpretação:}

- BIRADS 0: Solicitar US de mama ou compressão localizada ao exame mamográfico;

- $\quad$ BIRADS 1 e 2: Solicitar exame bianual ou anual a depender do risco para Ca de mama e idade da paciente;

- BIRADS 3: Solicitar exame a cada 6 meses;

- $\quad$ BIRADS 4 e 5: Encaminhar para mastologista para investigação histológica da lesão.

\section{Colpocitologia oncótica}

- $\quad 40$ a 65 anos: Exame anual. Se paciente tiver 2 exames negativos (classe I ou II sem HPV ou alterações celulares reparativas) para câncer de colo, repetir o exame a cada 3 anos (recomendação do Ministério da Saúde).

- $\quad>65$ anos**: se a paciente não tem fator de risco para Ca de útero (classe III ou NIC`s ou classe II com HPV), há aumento de falso positivo nos exames, por isso não há benefício em rastreamento após essa idade. É importante que a paciente tenha, anteriormente, 2 exames negativos para câncer para determinar o término do rastreamento para $\mathrm{Ca}$ de colo de útero com essa idade.

- Histerectomizadas (total): se a indicação da histerectomia foi por doença benigna, não há benefício comprovado na realização desse exame para rastrear neoplasia vaginal. Nesse caso, realizar apenas a inspeção da cavidade vaginal.

\section{Considerações:}

- Não fazer colposcopia de rotina nas pacientes. Apenas encaminhar para colposcopia as pacientes com exame colpocitológico alterado (classe III em diante ou NIC I em diante ou classe II com HPV).

- Cuidados na coleta: colher fora do período menstrual; evitar relação sexual, ducha vaginal ou uso de cremes vaginal nas 48 horas que antecedem o exame.

- Observar no laudo do exame colpocitológico se a amostra foi satisfatória, o que significa presença de células endocervicais; caso não tenha sido, é obrigatória nova coleta, pois um exame insatisfatório não tem valor algum. 
** $\Rightarrow$ Não há consenso quanto à idade para término do rastreamento. A idade de parada de rastreamento nos consensos americanos e pelas recomendações do Ministério da Saúde do Brasil é de 65 anos.

\section{Ultrassonografia}

$\mathrm{O}$ rastreamento ultrassonográfico para $\mathrm{Ca}$ de endométrio e ovário, em mulheres assintomáticas e com exame pélvico normal (sem presença de massas) não se mostrou eficaz para reduzir a mortalidade por essas doenças, por isso o rastreamento em massa não é recomendado para esse fim.

\section{Periodicidade:}

- Em todos casos novos (caso paciente tenha útero) com diagnóstico de síndrome do climatério ou menopausada;

- Sempre que houver indicação pela queixa ginecológica;

- Anualmente se houver sangramento irregular ou pós menopausa (não interessa a quantidade ou a coloração), IMC $\geq 30 \mathrm{Kg} / \mathrm{m}^{2}$, DM, HAS, em uso de tamoxifeno ou com antecedente de hiperplasia endometrial;

- Assintomáticas: não repetir, a menos que o exame pélvico mostrar alterações que necessitem de completar a investigação;

- Histerectomizadas: só realizar se exame ginecológico alterado.

Interpretação da espessura endometrial (se menopausada em uso ou não de TRH):

- $\quad \leq 4 \mathrm{~mm}$ : normal;

- 4,1-7,9mm: usar $10 \mathrm{mg}$ de AMP/dia por 10 dias (sem uso de TRH) ou suspender a TRH, esperar o sangramento e realizar o USTV após; se persistir espessura aumentada encaminhar para investigação em serviço terciário;

- $\quad \geq 8 \mathrm{~mm}$ : encaminhar investigação em serviço terciário.

Interpretação da espessura endometrial (pré menopausada em uso ou não de TRH): Realizar USTV na primeira semana após o sangramento genital

- $\quad \leq 4 \mathrm{~mm}$ : normal

- $\quad 4,1$ a 7,9mm: Repetir USTV em 3 meses.

- $\quad \geq 8 \mathrm{~mm}$.: Considerar fatores de risco endometriais. Se presentes, encaminhar para investigação em serviço terciário. Se ausentes, associar AMP 5-10 mg/dia, $2^{\text {a }}$ fase do ciclo por 3 meses e repetir US após.

\section{Densitometria óssea}

Sem fatores de risco: a partir dos 65 anos.

Em pacientes de alto risco (um dos fatores abaixo), iniciar a partir dos $\mathbf{4 0}$ anos:

- $\quad \mathrm{IMC}<20 \mathrm{~kg} / \mathrm{m}^{2}$;

- $\quad$ Menopausa precoce $(<40$ anos); 
- $\quad$ Fratura de punho ou de compressão vertebral;

- História familiar para osteoporose (documentada ou fratura);

- Uso sistêmico de corticoterapia por mais de 3 meses;

- Osteopenia aparente em exame radiográfico;

- Doenças causadoras de osteoporose secundária.

Periodicidade: não há um consenso sobre o intervalo ótimo para repetição do exame. A perda média óssea anual é de 0,5 a $2 \%$, enquanto os tratamentos mais eficazes levam a aumento da massa óssea de 1 a $6 \%$ em 3 anos de tratamento, por isso o rastreamento anual pode levar a interpretações falsas. Dessa forma, recomendam-se medidas seriadas a cada 3 anos de exame alterado para monitorizar tratamento ou progressão. Se o exame for normal, pode-se espaçar intervalo de repetição para 5 anos (NAMS, 2002).

\section{Interpretação: (T score)}

- $\quad$ Até -1: normal;

- $\quad$ Entre -1 a -2,5: osteopenia;

- $\leq-2,5$ : osteoporose

\section{TSH:}

A concentração sérica de TSH não aumenta em função da idade entre homens adultos, enquanto entre mulheres após 40 anos, as concentrações de TSH aumentam marcadamente.

Início: a partir de 40 anos.

Periodicidade: a cada 5 anos, caso exame normal. Se alterado, encaminhar ao endocrinologista.

\section{Glicemia de jejum}

Iniciar com 40 anos de idade o rastreamento para DM tipo 2.

\section{Interpretação:}

- $\quad<100 \mathrm{mg} \%$ : normal;

- $\quad \geq 100$ e < 126: Solicitar GTT 75g. Se a segunda amostra (2 hs) for maior que 200 $\mathrm{mg} / \mathrm{dl}$ é diabetes. Se estiver entre 140 e $200 \mathrm{mg} / \mathrm{dl}$ é intolerância glicêmica e se estiver abaixo de $140 \mathrm{mg} / \mathrm{dl}$ é apenas "glicemia de jejum alterada".

- $\quad \geq 126 \mathrm{mg} \%$ : se sinais / sintomas estão presentes (poliúria, polidipsia, polifagia), é diagnóstico de DM. Se sinais / sintomas ausentes, solicitar nova glicemia de jejum. Se $\geq 126 \mathrm{mg} \%$, é DM.

\section{Periodicidade:}

- $\quad$ Sem fatores de risco: a cada 3 anos; 
- Com fatores de risco (2 ou mais - quadro abaixo): anualmente;

- Com glicemia de jejum alterada ou intolerância à glicose: anualmente.

Fatores de risco para o Diabetes melito (excetuando-se a idade, pois todas pacientes têm idade $>40$ anos):

- História familiar de DM (pais, filhos e irmãos);

- $\quad$ Excesso de peso (IMC $\left.\geq 25 \mathrm{~kg} / \mathrm{m}^{2}\right)$;

- Sedentarismo;

- $\quad$ HDL baixo $(<40 \mathrm{mg} \%)$ ou Triglicérides elevados $(>200 \mathrm{mg} \%)$;

- HAS;

- DM gestacional prévio;

- Macrossomia fetal;

- Uso de medicações hiperglicemiantes (ex: tiazídicos, corticosteróides, betabloqueadores);

- $\quad$ Esquizofrenia.

\section{Lipidograma}

Solicitar colesterol total (CT), HDL e triglicérides (TG).

O LDL deve ser pedido, mas é calculado (e não dosado) de forma indireta pela fórmula abaixo: $\mathrm{LDL}=\mathrm{CT}-(\mathrm{HDL}+\mathrm{VLDL}) \quad \mathrm{VLDL}=\mathrm{TG} / 5$

\begin{tabular}{|c|c|c|}
\hline \multicolumn{3}{|c|}{$\begin{array}{l}\text { Valores de referencia des lipides para individuns }>20 \text { anos de } \\
\text { idade }\end{array}$} \\
\hline Lipides & Valores & Categoria \\
\hline \multicolumn{3}{|l|}{$\mathrm{CT}$} \\
\hline & 200 & Otimo \\
\hline & 200.239 & Limitufa \\
\hline & 240 & Alto \\
\hline \multicolumn{3}{|l|}{ LDL-C } \\
\hline & 100 & Otime \\
\hline & $100-129$ & Desajival \\
\hline & $130-159$ & Limi imf: \\
\hline & 190.189 & Alto \\
\hline & 2150 & Muito alto \\
\hline \multicolumn{3}{|l|}{ HDL-C } \\
\hline & -40 & Brixo \\
\hline & $=60$ & Alto \\
\hline \multicolumn{3}{|l|}{ TG } \\
\hline & 190 & Otimo \\
\hline & $190-200$ & Limitufe \\
\hline & 201.499 & Alto \\
\hline & 2500 & Muito alto \\
\hline
\end{tabular}


- $\quad$ Sem risco para doença coronariana: a partir de 40 anos*

* Com exame normal: repetir em 5 anos (até 55 anos, quando será anual a periodicidade);

* Com exame alterado: orientar mudança do estilo de vida** por 3 meses,após os quais solicitar novo lipidograma e, se alterado, encaminhar ao clínico ou cardiologista que estratificará os riscos para doença coronariana e decidirá qual a melhor freqüência de repetição do lipidograma para a paciente;

- Com fatores de risco para doença coronariana: a partir de 40 anos

* Com exame normal: repetir em 1 ano;

* Com exame alterado: orientar mudança do estilo de vida** e encaminhar ao clínico ou cardiologista que estratificará os riscos para doença coronariana e decidirá qual a melhor freqüência de repetição do lipidograma para a paciente (neste caso a depender dos fatores de risco e/ou dos níveis do LDL / TG o médico poderá iniciar com terapia medicamentosa sem aguardar os 3 meses da mudança do estilo de vida);

$* \Rightarrow$ Os consensos brasileiro (Sociedade Brasileira de Cardiologia) e americano (NCEP/ATP III) de dislipidemia recomendam iniciar o rastreamento com 20 anos de idade.

$* * \Rightarrow$ Mudança de estilo de vida: dieta, perda de peso e exercício físico.

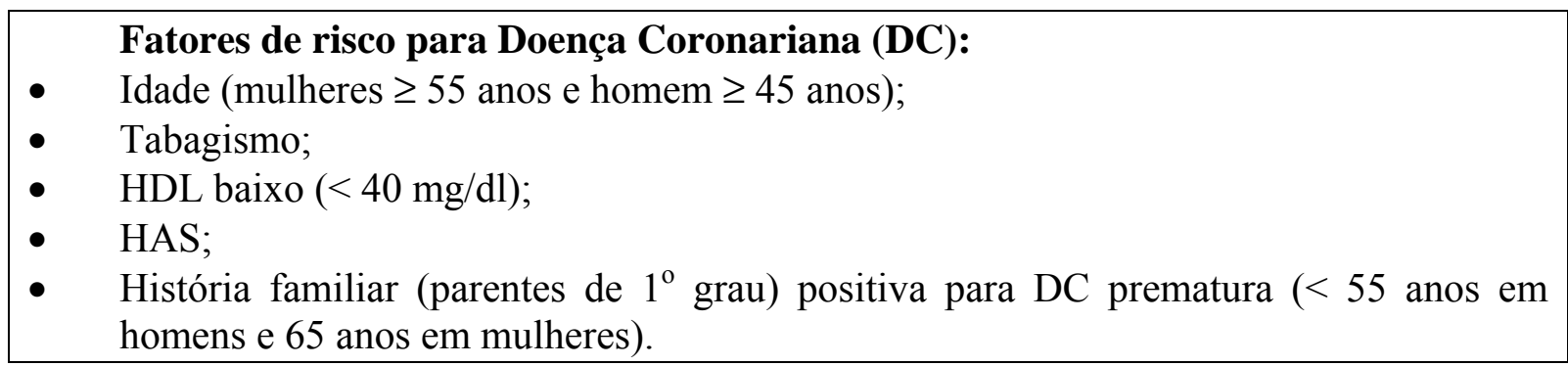

\section{Rastreamento para Câncer de cólon e reto}

- $\quad$ Sem fatores de risco: pesquisa de sangue oculto nas fezes anualmente a partir de 50 anos (INCA- Instituto Nacional de Câncer - Ministério da Saúde do Brasil)

- Com fatores de risco: encaminhar ao proctologista para rastreamento mais adequado.

Fatores de risco para Câncer de cólon e reto:

- Histórico familiar de câncer de cólon e reto (parente de $1^{\circ}$ grau);

- $\quad$ Síndrome de Lynch I e II (predisposição hereditária ao ca colo-retal não associada a polipose. Na forma tipo II, há também associação com câncer extra-colônico, como estômago, endométrio e ovário);

- $\quad$ Polipose adenomatosa familiar;

- $\quad$ Passado de pólipos intestinais;

- Colite ulcerativa. 


\section{Demais exames laboratoriais}

Sorologias: só deverão ser solicitadas se a paciente for sexualmente ativa e desejar exame ou tiver suspeita clínica de DST.

Urina tipo 1: não há benefício no rastreamento universal de pacientes assintomáticas visando diagnóstico precoce de câncer de bexiga.

Outros exames: só deverão ser solicitados se houver necessidade clínica, não fazendo parte da rotina para rastreamento em pacientes climatéricas (ex: paciente hipocorada: solicitar hemograma). Não há nenhuma evidência que justifique rastreamento universal de função renal, íons e função hepática para pacientes climatéricas assintomáticas.

\section{Resumo das orientações}

\begin{tabular}{|c|c|c|c|}
\hline Exame & $\begin{array}{l}\text { Idade de início no } \\
\text { climatério }\end{array}$ & Periodicidade & Comentários \\
\hline Mamografia & 40 anos & $\begin{array}{l}\text { 40-49: bienal } \\
>50: \text { anual }\end{array}$ & $\begin{array}{l}\text { Se } 40-49 \text { com fator } \\
\text { de risco: anual }\end{array}$ \\
\hline USTV & $\begin{array}{lr}\text { No caso novo } \\
\text { (menos em } \\
\text { histerectomizada) }\end{array}$ & \begin{tabular}{|l|} 
Se patologia ou \\
exame clínico \\
alterado
\end{tabular} & Vide recomendações \\
\hline $\begin{array}{l}\text { Colpocitologia } \\
\text { oncótica }\end{array}$ & 40 a 65 anos & $\begin{array}{l}\text { Anual. Se } 2 \text { exames } \\
\text { negativos para Ca: } \\
\text { trienal. }\end{array}$ & \\
\hline $\begin{array}{c}\text { Densitometria } \\
\text { óssea }\end{array}$ & $\begin{array}{l}65 \text { anos (sem fator } \\
\text { de risco). }\end{array}$ & $\begin{array}{l}\text { Exame normal: } 5 \mathrm{a} \\
\text { Exame alterado: } 3 \mathrm{a}\end{array}$ & $\begin{array}{l}\text { Se fator de risco, } \\
\text { iniciar aos } 40 \mathrm{a}\end{array}$ \\
\hline TSH & 40 anos & 5 anos & \\
\hline Glicemia de jejum & 40 anos & $\begin{array}{l}\text { S/fator de risco: } 3 \mathrm{a} \\
\mathrm{C} / \text { fator de risco: } \\
\text { anual }\end{array}$ & \\
\hline Lipidograma & 40 anos & $\begin{array}{l}\text { S/fator de risco: } 5 \text { a } \\
\text { C/fator de risco: } \\
\text { anual }\end{array}$ & $\begin{array}{l}\text { A partir de } 55 \text { anos, } \\
\text { o exame é anual. }\end{array}$ \\
\hline $\begin{array}{l}\text { Sangue oculto nas } \\
\text { fezes }\end{array}$ & 50 anos & $\begin{array}{l}\text { Sem fator de risco: } \\
\text { anual }\end{array}$ & $\begin{array}{l}\text { Com fator de risco: } \\
\text { ao procto }\end{array}$ \\
\hline
\end{tabular}

Outros exames laboratoriais só devem ser pedidos se houver quadro clínico que os justifiquem. 


\section{Anexo 3 \\ TERMO DE CONSENTIMENTO INFORMADO}

A senhora pertence a um grupo especial de mulheres que estão em um período da vida denominado Climatério, que se inicia algum tempo antes da Menopausa, que é a última menstruação. Quando a mulher apresenta a menopausa, ocorrem várias alterações no organismo devido à falta dos hormônios produzidos pelos ovários. Uma das mais importantes alterações que a mulher pode sofrer na menopausa é a osteoporose, que é uma fraqueza do osso que, conseqüentemente, pode se quebrar. Para evitar isso, existem várias medicações que podem ser usadas.

- A medicação que estamos propondo para a senhora usar é uma delas. Chama-se Tibolona e tem a capacidade de melhorar a osteoporose e as gorduras no sangue.

- A senhora está sendo convidada a participar voluntariamente de uma pesquisa que visa avaliar os efeitos dessa medicação. Sua participação nesse estudo será de três meses, e a senhora terá que comparecer para consultas e exames algumas vezes ao longo do estudo.

- Precisaremos fazer uma avaliação rigorosa de seu estado de saúde antes de lhe prescrever a medicação. Para isso, a senhora fará uma série de exames, como citologia vaginal, mamografia ( Raio-X das mamas), ultra som e alguns exames de sangue, que poderão ser repetidos ao longo do estudo.

- A pesquisa servirá para saber os efeitos dessa medicação sobre as mamas e isso vai ser feito por meio de exames de mamografia.

- O exame não causa dor e não traz prejuizos para a sua saúde.

- A mamografia é um exame que utiliza raios-X, mas os riscos associados a ela são baixos.

- Para a maioria das pessoas, as mamografias não causam grandes problemas, contudo, pode haver dor leve ou desconforto durante o exame e por pouco tempo após esse.

- Alguns desses exames trarão benefícios para a sua assistência médica nesse hospital e para controlar os efeitos da medicação no seu organismo, ao mesmo tempo em que servirão para os resultados de nossa pesquisa e poderão beneficiar outras pacientes no futuro.

- A medicação será tomada na forma de comprimidos (01 comprimido ao dia).

- Se a senhora sofrer algum problema de saúde relacionado ao uso da medicação fornecida durante o estudo como, por exemplo, náuseas, dores de cabeça, dores nas 
mamas ou sangramento genital entre em contato com Dr. Marcelo Ballaben Carloni, nas quartas-feiras, no ambulatório de Mastologia do Hospital das Clínicas, das 8 às 12 horas ou pelo telefone 633-9633 - Hospital das Clínicas de Ribeirão Preto no setor de pósgraduação da Disciplina de Ginecologia e Obstetrícia.

- Sua participação neste estudo é totalmente VOLUNTÁRIA, podendo se recusar a participar do mesmo ou interromper sua participação quando quiser, sem penalidades ou perda dos benefícios na sua assistência nesse hospital. 
$\mathrm{Eu}$, portadora do RG. abaixo assinada, tendo recebido as informações acima, e ciente dos meus direitos abaixo relacionados, concordo em participar da pesquisa 'AVALIAÇÃO DA DENSIDADE MAMOGRÁFICA ANTES E APÓS TERAPIA DE REPOSIÇÃO HORMONAL', conduzido pelo Dr. Marcelo Ballaben Carloni.

1. Tenho a garantia de receber resposta a qualquer pergunta ou esclarecimento a qualquer dúvida acerca dos procedimentos, riscos, beneficios e outros relacionados com a pesquisa e o exame a que serei submetida;

2. Tenho a liberdade de retirar meu consentimento a qualquer momento e deixar de participar do estudo, sem que isso traga prejuízo à continuação do meu cuidado e tratamento;

3. Tenho a segurança de que não serei identificada e que será mantido o caráter confidencial da informação relacionada com a minha privacidade;

4. Tenho o direito de ter acesso à informação atualizada durante o estudo, ainda que esta possa afetar minha vontade de continuar participando;

5. Tenho a disponibilidade de tratamento médico por parte da Instituição de Saúde, em caso de danos diretamente causados pela pesquisa.

Tenho ciência do exposto acima e desejo participar do estudo.

Ribeirão Preto, de de

Assinatura da paciente 